\title{
Making the case for a Material-Dialogic approach to Science Education
}

\author{
Lindsay Hetherington ${ }^{\mathrm{a}}$, Mark Hardman ${ }^{\mathrm{b}}$, Jill Noakes ${ }^{\mathrm{a}}$, Rupert Wegerif ${ }^{\mathrm{c}}$
}

${ }^{a}$ Graduate School of Education, University of Exeter, Exeter, UK

${ }^{b}$ Institute of Education, University College London, London, UK

${ }^{c}$ Faculty of Education, University of Cambridge, Cambridge, UK

Lindsay Hetherington, Graduate School of Education, University of Exeter St Luke's

Campus, Exeter, EX1 2LU, UK. L.Hetherington@exeter.ac.uk.

Lindsay Hetherington (@lindsayhether, https://orcid.org/0000-0002-9811-7666) is a Senior Lecturer in Education at the University of Education. Her research interests are in relational, creative and material approaches to science education and teacher education. She uses a range of methods as relevant to these questions, from survey studies to new materialist diffractive analysis. Lindsay co-leads Initial Teacher Education at the University of Exeter and is a member of the Centre for Research in STEM Education.

Mark Hardman (@MAHardman, https://orcid.org/0000-0001-5920-3150) is Associate Professor of Education at the Institute of Education, University College London, where he leads the Centre for Teachers and Teaching Research. He is fascinated by the processes involved in learning and use insights from complexity theory, neuroscience and conceptual change research to better understand these. He is also interested in how teachers engage with educational research.

Jill Noakes is an Associate Lecturer and ESRC-funded PhD student at the University of Exeter. Previously a Physics teacher, she is now involved in science initial teacher education. Her PhD study combines cultural-historical activity theory with the notion of agency to explore schools' engagement (or otherwise) with STEM project-based learning. She is also involved in a project exploring factors affecting the success of initial teacher education students.

Rupert Wegerif (@ rupertwegerif, https://orcid.org/0000-0003-2278-224) is Professor of Education at the University of Cambridge where he mostly teaches educational psychology. His research focuses on education for dialogue in the context of the Internet Age. He researches dialogic theory in education and ways of teaching through dialogue and teaching for dialogue in classrooms with and without technology. He is co-lead with Sara Hennessy of the Cambridge 
Educational Dialogue Research group (CEDiR) and founder and co-convenor of the Educational Theory Special Interest Group (SIG) of the European Association of Research on Learning and Instruction (EARLI). 


\section{Making the case for a Material-Dialogic approach to Science Education}

Science is concerned with understanding the world. As such, engaging with the materiality of that world is integral to both empirical experimentation and theorizing within science. However, it has been recognised for some time that the way scientists learn about the world and the way that young people learn about science cannot be simply equated. This difference has been pronounced in recent decades by the dominance of constructivist and social-constructivist theories of learning, which focus on the development of concepts in the minds of people. Whilst these theories have yielded insight into the complexity of learning, the role of the material remains undertheorised, both within practical science inquiry, but also in relation to the broader materiality of classrooms. Through a detailed critical literature review, this paper demonstrates the need for a stronger theoretical frame through which to understand the role of the material in the learning and pedagogy of science. Building upon the gaps and possibilities that this review reveals, we outline a new material-dialogic theory via a synthesis of Barad's Agential Realism and Bakhtinian dialogic theory. The significance of this paper lies in offering a theoretical basis for more effective practice.

Keywords: dialogic pedagogy; new materialism, Barad, science education, practical work

\section{Introduction}

In schools throughout the world science is taught and learnt in rooms that are quite distinctive from the rest of the school. In updating a review from 20 years earlier, Hofstein \& Lunetta (2004) demonstrated the central and distinctive role given to laboratories within science education. This has persisted since the inception of formal 
schooling in many countries. School laboratories are places not just where materials (living and non-living) are subjected to experimentation, but also where you find specialist equipment, physical models, drawings and diagrams. Moreover, the material resources you might find in other classrooms are also present: information technology, blackboards or whiteboards, textbooks, exercise books, stationary, furniture, walls and windows and, of course, people. Whilst other subject disciplines also engage with materials (for example art or technology), science is perhaps different in that it is primarily engaged in explaining the materiality of the world, or the world viewed as matter and energy.

Investigating the world through practical work thus holds a central, crucial, place in science education. Many teachers view practical work as essential to science education, and Abrahams \& Saglam (2010) found that this has persisted over the last 50 or so years, with little difference by subject specialism, gender or teacher experience. Whilst we suspect that many science teachers don't question the use of practical work, a rationale for its use, reported internationally, is its relationship to the teaching of 'scientific method' in the generation of new knowledge (Swain, Monk, \& Johnson, 1999).

The overwhelming support for practical work in science education faces both empirical and theoretical challenges. Empirically, the impact of practical work on students' learning remains unclear: much practical work has been shown to be ineffective in developing pupil learning in science (Abrahams \& Millar, 2008; Berry, Mulhall, Gunstone, \& Loughran, 1999). Theoretically, practical work, particularly in the context of inquiry based science education (IBSE), has been primarily underpinned theoretically by constructivism and social constructivism and this has become an 
accepted and largely unquestioned stance (Hodson, 2014). Dissenting voices have been present for more than 20 years however; with Osborne arguing that constructivism in science education 'has confused the manner in which new knowledge is made with the manner in which old knowledge is learned, assuming that the two are one and the same thing' (Osborne, 1996, p. 53).

Whilst constructivism provides an account of how young people develop different understandings, it does not offer guidance on adjudicating between them, counter to scientific processes (such as empirical hypothesis testing). Osborne also noted how constructivism rejects what in the UK we might call 'didactic teaching', or 'direct instruction'. This has been the site of much recent criticism of pedagogies associated with constructivism, for example Kirschner, Sweller, \& Clark’s (2006), arguments against inquiry based pedagogies in favour of direct instruction.

Whilst it is not possible to give a full account of constructivism in science education within this article, we will show through literature review that the practical context is often conceived as providing opportunity for individuals to develop an abstracted, scientifically accepted conceptual understanding. In social constructivism, individuals are supported in their efforts to grasp the concepts taught with support from others, but ultimately the focus is on the individual's ideas. By focusing on the development of concepts, constructivism separates learning from the practical material that learners are engaging with and, indeed, from their own bodies. Constructivist accounts of science education are therefore also challenged by research into embodied cognition, which provides a different way of theorizing the key role of hands-on activities in Science, Technology and Engineering (Wesberg \& Newcombe, 2017).

The challenges to constructivism in science education lead us to propose that the theory underpinning the specific role of the material in learning and teaching of science 
needs an update. Providing a theoretical frame for science education that focuses on the relation between matter and meaning is therefore the primary focus of this paper. Whilst we develop our proposal more fully in the second half of this paper, it is worth here outlining the theoretical frames that we will draw upon. Firstly, we will draw on the established body of literature around dialogic pedagogy. Secondly, we will draw on the growing interest in the onto-epistemological stance of 'new materialist' theories, particularly that of Karen Barad.

We suggest that the strengths of 'dialogic pedagogy', with its strong theoretical grounding, could be brought to bear in relation to the effective use of learning science (Mercer, Dawes, Wegerif, \& Sams, 2004; Ruthven et al., 2017). Dialogic pedagogy is able to account for how pupils engaging in science learning will be simultaneously talking and thinking as well as using their bodies to sense and manipulate their environment. Classroom dialogue between students and teachers and by students in groups can be a powerful means of eliciting, challenging, scaffolding and developing pupils' thinking. Much research into classroom dialogue has been underpinned by Bakhtinian theory (Mercer \& Howe, 2012; Wegerif, 2011a) and this has influenced how researchers and teachers think about talk and learning as a relational activity (see for example http://www.robinalexander.org.uk/dialogic-teaching/). A recent randomised controlled trial in the UK has demonstrated that pupils make more progress in English, Maths and Science using Alexander's approach to dialogic pedagogy (Jay et al., 2017). However, current theories of dialogic education tend to focus on verbal dialogue and fail to adequately take account of the role of interaction with physical objects and the material world.

To address this would require a theoretical frame which extends the traditional view of dialogue as verbal and written, to also include classroom 'dialogue' with the 
material resources and environment of classrooms. Specifically, this focuses on how materials and dialogue 'intra-act' (a term we will develop below), suggesting the relevance of new materialism (Coole and Frost, 2010) to addressing the problem we frame here. Recent work deploying new materialist theory has begun to unpick an unquestioned reliance on constructivism and the individualist onto-epistemological stance, to develop perspectives in which the active role of material, body and mind create meaning together (see e.g. Cowie, Otrel-Cass, \& Moreland, 2015; deFreitas \& Palmer, 2016).

Bringing together an understanding of dialogic pedagogy and new materialism therefore has the potential to offer a well-developed and well-supported account of dialogue within the classroom but extend it to consider not just linguistic but all material intra-actions within the classroom. Moreover, by bringing together the Bakhtinian basis for considering dialogue and Barad's account of emergent meaning, we hope to develop a theoretical frame equal to not only challenging constructivism, but also allowing insight into meaning-making through the 'dialogue' of matter, in its broadest sense, within science classrooms.

To develop this position, the first part of this paper reports on a critical review of literature about effective practical work in science, the role of dialogue, and the role of the material with respect to learning science. We show that this aspect of science education remains under theorised and under researched, particularly with respect to the relationship between classroom dialogue and the material nature of practical activity. In the second half of the paper, we address the need for a clear theory to guide practice by synthesizing two streams of thought: dialogic theory and the 'new materialist' theory of 'Agential Realism' developed by Karen Barad (2007). We thus put forward the case for what we call a 'material-dialogic pedagogy' for science education. 


\section{Literature Review: The role and impact of the Material in Science Education.}

Our review of the literature is presented in two parts. In the first, we focus in on practical work as a crucial aspect of the material nature of science education whose very materiality has often been sidelined in science educational research (Scantlebury \& Milne, 2019). Secondly, we describe research that has focused on the material in science education more broadly, including the classroom environment, technologies and artefacts as well as practical materials.

We identified articles for inclusion in the review using a key word search in the databases Education Research Complete, the British Education Index, ERIC and inputting key words into Google Scholar. Key words used were Practical work, Practical activity, Experiment, Laboratory work, Manipulation/Manipulatives, Laboratory environment, Embodiment, Physicality, Physical Models and Gestures in combination with the term 'Science Education'. The reference lists of articles resulting from the database searches were also checked to identify further relevant literature from the period of interest. Articles were sought from 1998 to present, to cover a substantial period of recent research. We selected 1998 as a cut-off since it was the year of writing for a new Science curriculum in the UK that focused on 'How Science Works' as a strand of scientific inquiry, as well as the date of publication of a key document 'Beyond 2000' (Millar \& Osborne, 1998), which reviewed the status of science education and included a series of research based recommendations for teaching practical work. Since the focus of our work is on school science, articles focusing on undergraduate teaching were excluded unless they explicitly focused on the relationship between conceptual learning in science, laboratory activity and dialogue or materiality. Abstracts were used to select articles relevant to the questions under review, which we then read in full. Key articles of relevance to the questions at hand were checked for references and subsequent citations that may have been missed in the initial database 
search. We have structured the review according to the research questions above with respect to practical work and then thematically according to various types of material interaction in school science, namely models and pedagogical artefacts, gestures, technology, and the laboratory environment.

Before we continue to discuss the theoretical basis of practical work in school science, a note on the terms we are using in this paper: As Hofstein and Lunetta (2004) note, too often the terminology around the hands-on activities undertaken by pupils in schools are poorly defined, leading to ambiguity in understanding the evidence presented (for example with respect to the level of teacher guidance in studies of 'inquiry learning'). For the purposes of this review, we define 'practical work' as 'experiences in school settings where students interact with materials to observe and understand the natural world' (Hofstein, Lunetta, \& Clough, 2007, p. 394). This definition takes in a wide range of activities, including students working individually, in groups or as whole classes, undertaking investigative activity or engaging with secondary sources of data such as spectra, or 'virtual labs' where students use digital technologies to engage in observation or inquiry at a distance. We have maintained this breadth of definition since in all the activities, pupils are engaging with the 'materiality' of the natural world and therefore with science, thus they are of relevance to the subject of this paper.

\section{Practical Work in School Science}

In our review of relevant literature with respect to practical work, we aimed to answer these key research questions:

- What are the reported purposes of practical work?

- How effective is practical work for pupils' learning science? 
- What is the relationship between practical work and classroom talk?

- How is the use of materials in practical work currently understood?

By exploring these questions, we intended to uncover the theoretical basis on which practical work is supported and evaluated in science, and explore the links between this basis, classroom dialogue, and the material nature of practical science.

What are the reported purposes of practical work?

Papers published in the last twenty years show that the reported purposes of practical work have not shifted a great deal over time, with findings similar to those reported in substantial reviews of literature on the subject by Lasarowitz and Tamir (1994), Hodson (1993) and Hofstein and Lunetta (1982). A common thread in research into teachers' perspectives on practical work in science is that teachers across a wide range of international contexts are largely in support of its use, viewing it as essential. For example, Leach and Paulsen's (1999) review indicated teacher's support for practical work across a range of studies internationally, which has continued to be evidenced in later studies, for example Abrahams \& Saglam's (2010) work in the UK and Dikmenli's (2009) study in Turkey. It is worth further exploration into the basis of these claims however, in order to elucidate their theoretical basis.

Teachers' reasons for undertaking practical work were variable, although a range of common themes can be synthesised. Swain et al. (1999) found that the purposes were dependent on the curriculum focus, with practical work used in investigations, to illustrate concepts or to promote factual recall. Common to all different curricula, however, was the need to use practical work to teach pupils about the use of 'scientific methods' to generate new knowledge. Wellington and Ireson (2017) classified the reasons teachers give for the inclusion of practical work according 
to 'cognitive', 'affective' and 'skills-based (scientific and transferrable)' rationales. Classifying teachers' rationales in this way offers a useful approach to synthesising the literature for the purposes of this paper, as the way in which practical work is entangled with (embodied) dialogue and other classroom materials will impact on these purposes in different ways. We therefore utilise headings below inspired by Ireson's classifications, whilst bearing in mind that any theoretical stance must be open to the unanticipated phenomena that may emerge, beyond the planned purposes identified by teachers.

\section{Disciplinary Learning}

In most school science curricula pupils are expected to learn about both the body of knowledge (i.e. the disciplinary content) and the way in which that knowledge is developed (i.e. the processes of science). Research shows that teachers in a range of international contexts advocate the use of practical work in order to aid pupils in their construction of scientific knowledge (Çımer, 2007), through engaging in investigative or inquiry-based activities. Practical activities are also used to illustrate key concepts and verify theoretical knowledge (Dikmenli, 2009; Ferreira \& Morais, 2014), and apply acquired knowledge to new contexts (Çımer, 2007). Although it is easy to separate learning content from learning processes and skills as purposes of practical activity, it is clear that the same activity can be used to develop an understanding of content and skills together. However, the effectiveness of using activities to promote understanding of scientific processes is questioned within the literature. Despite many teachers aiming to use practical work to develop pupils' knowledge of such processes, including understanding 'scientific method' (Cheung \& Yip, 2004; Swain et al., 1999) and developing their laboratory skills (Roscoe, 2007). Donnelly, O’Reilly and McGarr 
(2013) highlight that analysing and critiquing the experiment is often viewed as an 'add on' to practical work rather than integral to it. This is in line with other findings, that despite teachers' intentions, practical work is often used in a rather 'recipe' based style simply for the confirmation of 'findings' to illustrate the theoretical knowledge that is the focus of the lesson (Abrahams \& Reiss, 2012). The literature thus shows that claims are made about effective exploitation of practical activities for construction of knowledge, conceptual development and an understanding of the processes of science. However, the failure to achieve this is blamed on multiple reasons that often relate to a lack of time to cover the curriculum content, a lack of expertise and confidence and concerns over the behaviour of students and the extent to which the practical activity is safe for students to undertake (Science Community Representing Education [SCORE], 2008; Yoon \& Kim, 2010). Interestingly for our later consideration of dialogic pedagogy, Yoon and Kim (2010) found that for novice teachers a lack of interaction between the students and teacher caused teachers dilemmas in making use of practical activities.

There is much debate within the educational research about the effectiveness of pedagogical strategies such as discovery learning, inquiry-based science education and direct instruction (Harlen, 2013; Kirschner et al., 2006). We do not have space to explore this ongoing debate here in depth: suffice to say that since science teachers view practical work as important in disciplinary learning and use a range of pedagogical strategies to support this, it is important to consider how disciplinary learning through practical work and these strategies together impact on learning.

A review of the literature shows that learning the knowledge, skills and processes of science forms a principal aim of using practical activities for many science teachers. Yet the debate about the specifics of this is not furthered by the 
constructivist framing of knowledge construction or conceptual development, which does not provide a basis with which to choose any one approach over another. Whilst the logistical issues of inquiry activities are often cited as problematic, this rarely focuses to the level of exploring how pupils are learning from particular activities, and what they are learning from them. In focusing on the intangible development of concepts and understanding, the literature pays little attention to the specific interactions of matter, including the learners, their bodies and the materials with which they interact.

\section{Motivation}

Despite the issues raised in making effective use of practical work, teachers regularly report that one of their aims in planning practical activities is to motivate pupils, as pupils enjoy it (Abrahams, 2011; Helliar \& Harrison, 2011; Kapenda, KandjeoMarenga, Kasandra, \& Lubben, 2002). In reality, the motivational element of practical work appears to be short term (Robin Millar \& Abrahams, 2009), with engagement in that particular lesson likely to be raised but long term uptake of science remains problematic (Potvin \& Hasni, 2014). Abrahams (2011) raises this question: if pupils are interested in and motivated by practical work, why are there still problems in the uptake of science subjects in post-compulsory education in the UK? It may be that this can be explained by looking to findings that show pupils are interested in science (which may be in part due to the practical element) but do not see it as something 'for them' (DeWitt, Archer, \& Mau, 2016). A further interesting question with respect to the motivational dimension of science practical work lies in its' relationship to scientific creativity (Meyer \& Lederman, 2013). The fostering of creativity has been identified as a purpose in including practical work (Haigh, 2007), but science is regularly viewed by pupils as not inherently creative, being more focused on the learning of facts (Osborne 
\& Collins, 2001). Highlighting the creative nature of the discipline of science therefore represents an important site for development when theorizing pedagogies of practical work.

How effective is practical work for learning science?

By considering how effective practical work is in supporting learning in science, we can evaluate something of how well its current theorization supports effective pedagogical strategies. For some time however, the effectiveness of practical work has been questioned. A series of studies in the 1980s and 1990s found no consensus on the impact of practical work on learning (Martindill \& Wilson, 2014). Numerous more recent research studies have explored the effectiveness of a range of pedagogical strategies that make use of practical activities, from inquiry activities (Harlen, 2013), use of questioning (Hofstein et al., 2007; Kind, Kind, Hofstein, \& Wilson, 2011), out of school learning (Itzek-Greulich \& Vollmer, 2017), virtual or remote laboratories (Donnelly et al., 2013; Lowe, Newcombe, \& Stumpers, 2013), and pupil grouping (Little \& León de la Barra, 2009), amongst others. The wide range of studies exploring this issue have not, however, found a straightforward answer to the question of how effective practical work is for learning science, or what pedagogical approaches improve its' impact, underpinned by what theoretical basis. Martindill and Wilson (2014) combined a large scale survey with an in depth case study to explore pupils' perceptions of the impact of practical work as well as its role in learning science. They found that where practical work was included, outcomes were improved, and identified the reasons as supporting visualization of abstract concepts, providing stimulus for recall, fostering collaboration (with its associated gains), and providing a motivational classroom environment. In contrast, in two large studies, opportunities to connect observations made in practical activities to scientific knowledge often went unexploited 
by teachers (Abrahams \& Millar, 2008; Abrahams \& Reiss, 2012; Abrahams, Reiss, \& Sharpe, 2013). It seems that it is not the presence of practical work in itself that makes a difference but how that practical work is taught. Somewhat unsurprisingly, it seems that where practical activities are used in the context of particular pedagogical strategies, they are more effective. For example, the 'Getting Practical' project aimed to increase teachers' use of strategies that link practical work to conceptual development, through enabling pupils to be both 'hands on' and 'minds on'. This was found to be only partially successful in embedding change in teachers' practices (Abrahams, Reiss, \& Sharpe, 2014), but did show promise in providing clear pedagogical strategies.

The need for greater focus on specifics with respect to the effectiveness of practical work supports our contention that practical work requires theorizing not just at the level of educational aims or the development of conceptual understanding, but requires a theoretical frame equal to the specifics of how people learning and what they learn from in classrooms.

It has been suggested that much use of practical work is ineffective because the rationale for its use is not focused (Hart, Mulhall, Berry, Loughran, \& Gunstone, 2000): perhaps unsurprising given the multiplicity of purposes for practical work identified above. Berry et al. (1999) also found that there was limited learning through practical work where there was a lack of application of the practical work to understanding scientific processes, with teachers and pupils focused on task completion. This is linked to the 'recipe style' approach found in the Abrahams' studies. Again, this suggests a more specific account of learning in relation to practical work is required.

Berry et al. advocate concept mapping and further research has shown how the careful use of representations, instructions and diagrams can support learning through practical activity. For example, Haslam and Hamilton (2010) argue that the use of 
images in instructions for practical work increase pupils' learning. As well as visual cues, Clough (2002) found that discussion and questioning were key to increasing the effectiveness of practical activities, mirroring Martindill and Wilson's (2014) case study. The identification of these particular pedagogies that appear to aid the effective use of practical work is important because they have in common ways of using materials (both the materials of practical science themselves and in the use of specific material pedagogical tools such as pictorial instructions and concept maps) alongside dialogic elements such as questioning and collaboration. This highlights the need to bring together these two elements in theorizing effective use of practical activities in science. In the final section of this review, we explore the extent to which these links have already been investigated, before turning to articulate our theoretical foundation for suggesting a particular pedagogical approach ${ }^{1}$.

What is the relationship between practical work and classroom talk in learning science?

Research that explores the relationship between practical work and classroom talk has focused on teachers' use of questioning (Chin, 2007), the role of practical work in supporting pupils' argumentation in science as a feature of scientific processes (Gott \& Duggan, 2007; Kind et al., 2011; Osborne, Erduran, \& Simon, 2004) and the relationship between talk and thinking during practical science lessons (Andersson \& Enghan, 2017; Mercer et al., 2004; Thomas \& McRobbie, 2013). These studies maintain a primary focus on the talk taking place: where included, the practical was the object of the dialogue but the dialogue was the subject of study.

\footnotetext{
${ }^{1}$ A note on terms, since 'pedagogy' and 'didactics' are used distinctively in European literature but less so in the UK and US: we use 'pedagogy' to indicate a theoretical basis for practice rather than a practice in itself.
} 
The role of teacher questioning is important with respect to effective practical work because it is the means by which teachers lead pupils through explanations, prompt their thinking and assess learning. By extending the 'Initiation-ResponseFeedback' (IRF) questioning pattern through her studies of questioning in science, Chin used a 'questioning based discourse analysis framework' to explore how teachers fed back to students on their responses to teacher questions (Chin, 2006, 2007). She found that some feedback tactics were more likely to encourage students' thinking and thus, where questioning was focused on practical activities, were more likely to prompt effective use of the practical for conceptual learning. One such tactic was labelled 'focusing and zooming', where the teacher's questioning is responsive to students answers and used the practical context to 'focus in' on detailed explanations and 'zoom out' to broader applications of the concepts discussed. More broadly, Chin's studies of questioning paralleled those of Mercer et al. (2004) in that a shift from authoritative responses to more dialogically-oriented questioning strategies were more likely to foster pupils' scientific thinking (Van Booven, 2015). The hallmark of dialogically-oriented questioning was in the use of the feedback stage in a non-evaluative manner, to restate, reframe open out ideas to pupils for further response in a sensitive, teacher-led but not teacher-dominated questioning strategy. The importance of such teacher-student interactions in practical activities to scaffold pupils' explanations using their observations was highlighted as crucial in ways that go beyond simply the talk taking place. Suggesting that 'it is not only what the teacher says, but how the teacher acts' that is important in aiding students learning from practical activities (Högström, Ottander, \& Benckert, 2010. p. 505), through the ways in which they direct students' 
attention to the purposes of the activity. This point is an important one, to which we will return in considering the embodied nature of material-dialogic pedagogy in section 3.

The relationship between questioning and argumentation in science is a close one, with teachers' use of questioning being key to developing argumentation skills, as well as their willingness and capacity to open up 'space' for students to generate their own questions. Argumentation is crucial in science learning because it represents an important part of the process of science: namely, the ability to make an argument based on evidence (Osborne et al., 2004). This evidence may be from a secondary source but is often drawn from primary observation of an experiment or practical investigation. Pupils use their scientific knowledge along with direct observation to explain phenomena, arguing their case by drawing on warrants for knowledge (Gott \& Duggan, 2007; Toulmin, 1972). Scientific argumentation in science lessons could be an individual pupil activity but is more likely to take place collaboratively through the medium of classroom peer discussion or dialogue (Kind et al., 2011). The quality of peer argumentation is not necessarily improved by the use of data derived directly from practical activities, however, Kind et al. (2011) compared argumentation between three conditions: collecting complex data and drawing conclusions, collecting data to address conflicting hypotheses, and using pre-collected data in a paper-based activity. They found that the latter prompted the most developed argumentation, as pupils did not make such critically analytical use of their own data. We contend that developing a pedagogy drawing on material and dialogue together might have potential to address this issue.

Questioning and argumentation form key aspects of science education, but we might situate these within broader consideration of dialogic interactions within science classrooms and laboratories. In exploring the relationship between dialogic pedagogy 
and science, Mercer et al. note the importance of pupils' engaging in science investigations, experiments and activities in school science, but suggest that teachers would benefit from guidance about how to foster effective collaborative classroom dialogue (Mercer et al., 2004). Their study showed that teaching pupils how to use 'exploratory talk' effectively for group reasoning in the context of a computer-based science investigation led to improved outcomes and demonstrates the effectiveness of dialogic pedagogy for science teaching and learning. However, once again, the pupils' use of talk was the prime focus of the study, with the investigation the context of the talk (in this case, a computer interface rather than a practical).

There is little research into how teachers might better link dialogue with practical work in order to support learning. One counterpoint is Thomas and McRobbie's (2013) analysis of a case study of pedagogical change, in which a teacher shifted towards using experiments as a source of ideas for discussion, rather than consolidation of content presented through a text book. Changing the emphasis in the way in which classroom materials (both the textbook and the experiment) were used in relation to classroom talk radically changed the teaching and learning occurring in the case, but importantly required that both teacher and students were convinced of the impact of the change. Whilst this provides a tantalising hint that linking dialogue and practical work may benefit learning, this single case study does not provide a fully coherent foundation for theorising these links.

\section{What other material interactions are significant in the science classroom?}

Experiments are not the only way that learners interact with the material world in the science classroom. Moreover, framing pupils as interacting with the material world disguises the fact that learners' bodies are themselves part of the material world. Alsop (2011) points out that the embodied experiences of both teachers and learners and 
the corporeal dimensions of pedagogy have not received sufficient attention. He also highlights the fact that scientific intelligence is generally attributed solely to the brain while the body is either removed, such as when an 'eye' appears in optical diagrams, or framed as a passive object of study represented by anatomical drawings and biological systems. Alsop goes on to claim that 'in the field of science education, disembodiment is the institutional standard' (p.615). In contrast, the significance of the affective body, a body that resists our attempts to exclude it from our understanding of the world, is indicated by the history of science (Lawrence \& Shapin, 1998) but also by some recent studies on bodily experiences in the science classroom. For example, in the paper that inspired Alsop's reflections, Orlander and Wickman (2011) draw attention to how encounters between bodies are important for meaning making in science education. Their study of the bodily experiences, expressions and interactions of secondary school students studying eye dissection and sex education reveal a complex interplay between the physical, emotional and cognitive aspects of the science classroom that are essentially inseparable.

Taking a rather different approach, Gough (1998) invites us to view school laboratories as theatres of representation in which material artefacts and apparatus are used as props around which various scripts can be constructed to represent science as a cultural practice. He suggests that if pupils are encouraged to see the school laboratory as a stage, only a contrived simulation of real science, they might be more likely to 'play' with the artefacts, to experiment with translating back and forth between scientific and colloquial language, and to recognise that different scripts for practical work are tailored to achieving particular audience effects.

These examples point the way to alternative conceptions of materiality in school science, and this section aims to broaden the scope of the literature review beyond 
debates about practical work and towards a more holistic understanding of how the material world impresses itself upon us as an agential and dialogic presence in the science classroom.

Models and pedagogical artefacts

School laboratories are replete with artefacts, but not all are intended for the purposes of experimentation. Physical models, whether created by pupils or supplied by the teacher, are commonplace in science instruction and provide an illuminating perspective on the role of material artefacts in learning. Models take many forms and have many uses (Harrison \& Treagust, 2000) and Toon (2011) argues that we need to pay much greater attention to the role of physical, three-dimensional models in particular. When learners actively participate in modelling, for instance when they build and manipulate molecules using ball and stick models, Toon suggests that we view the models as if they are props in games of make-believe. Users of the models (including trained scientists) become participants in the fiction that they are in fact manipulating a real molecule and can literally feel how it resists certain configurations and movements.

Model based learning and modelling-based teaching are supported by considerable bodies of research within science education, and Gilbert \& Justi (2016) describe a shift in the consideration of models as purely representational of scientific concepts, to the recognition of models as 'artefacts' within science classrooms, through which children learn. Some important observations can be gathered from those areas of the literature that deal specifically with concrete, physical models. For example, Frejd (2018) views physical artefacts such as figurines, maps and printed photographs as semiotic resources for pupils' reasoning about evolution and adaptation. The children in his study picked them up, gestured with them and manipulated them in ways that were 
fundamentally constitutive of their dialogue with the interviewer. Frejd concluded that the artefacts functioned simultaneously as 'resources providing meaning and communicative tools in their meaning making process' (p.262) (author's emphasis).

A body of research examining young children's understanding of the Earth, Sun and Moon has provided a rich insight into the interplay between talking, drawing and manipulating physical objects as children develop their thinking. Drawing on the work of various neuroscientists, Bryce and Blown (2016) argue for a multi-modal understanding of how children think and learn about elementary astronomy: 'A picture that we draw, or a model that we make, neither precedes nor follows an explanation that we give in attempting to indicate what we mean' (Bryce and Blown 2016, p.53). Meanwhile, having access to a globe while answering an interviewer's questions about the Earth enabled children "to reflect while talking by using (the physical tool) as a prosthetic device for thinking"' and led to a far greater proportion giving scientifically acceptable explanations (Schoultz, Saljo, \& Wyndhamn, 2001, p.115). Vosniadou, Skopeliti, and Ikospentaki (2005) responded to this finding by exploring how children's prior knowledge shapes the way they interact with the globe, an essentially cultural artefact. They raised concerns that the presence of the artefact constrained the children's thinking during the specific dialogue with the interviewer, but did not necessarily alter their internal explanatory structures, potentially giving rise to inconsistencies in their thinking. Nevertheless, there are grounds for considering physical artefacts as an important extension of what may otherwise be considered to be solely mental or verbal reasoning processes.

Rivet and Kastens (2012) point out that models are particularly important for teaching about Earth and Space, where student interaction with the actual phenomena in question is impossible. They note, however, that 'it is commonly perceived that the 
model "tells" the concept, rather than being viewed as a tool for supporting the development of understanding' (p.715). This sense of a simplistic one-way communication from model to learner is highly problematic in pedagogic terms, as students require substantial support to enable them to 'see' the correspondence between entities and to manipulate the model in a way that guides their reasoning process. It also does not reflect how models are used by practicing scientists as a mode of inquiry. Watson and Crick famously developed their double helix structure of DNA as a physical model and a theoretical model simultaneously and in dialogue with other scientists (Watson, 1968), and in a similar fashion it has been suggested that modelbased learning is most effective when learners have the opportunity to test and critique their own models and those of others through collaborative group work (Coll, France, \& Taylor, 2005).

\section{Gestures}

In a review that encompasses much of their earlier work and extensive observations of science classrooms, Roth and Lawless (2002) have argued for much greater attention to be paid to the role that gestures play in the development of learners' scientific language and explanations. Gestures were observed in relation to the physical objects and representations that they referred to, and the researchers compared this with the language that was used at the same time. The authors suggest that students' conversations are enhanced by the presence of material objects and events as 'these provide a phenomenal ground against which students can enact metaphorical gestures that embody (give a body to) entities that are conceptual and abstract' (p.288). They observed that when pupils were asked to explain something that they were still learning about, their gestures often slightly preceded the formation of the accompanying verbal 
discourse, perhaps indicating that gestures in some way scaffold the scientific language that pupils construct. This finding was echoed by Singer, Radinsky, and Goldman (2008) who found that when reasoning about plate tectonics in small groups, sixth graders produced all kinds of embodied representations and 'copied, manipulated, and added to each other's gestures as they co-constructed the meanings of these abstract concepts' (p.367).

Gestures have been specifically analysed by Roth and Welzel (2001) as a bridge between laboratory activities and scientific discourse. In so doing they address the concern that the link between hands-on activities and understanding of abstract concepts has not been well established. When pupils had access to the original materials, they picked them up and used them in their gestures as they explained the experiment. In the absence of these, they often substituted other objects such as pens as representational proxies for the materials they referred to. On this basis, the authors recommend that students should be given the opportunity to explain the results of laboratory experiments while they are still in the lab since the materials serve as mediating tools in their construction of meaning.

As well as gesture, Pozzer-Ardenghi and Roth (2004) reveal how a range of body orientations are used by teachers and lecturers in science classes to focus attention on the salient features of photographs, charts, diagrams and other visual inscriptions. These embodied actions provide connections between the uttered words of the instructor and the material world that the visual resources are intended to represent, leading to a more specific and constrained interpretation of meaning. The practice of projecting images rather than (or in addition to) disseminating photocopies or books is therefore recommended, as gestures can be used to bridge the gap between two dimensional representations and the real world. Based on a similar argument that gestures and 
actions provide multi-directional pedagogical linkage between phenomena, mental models, concrete models and diagrams, Padalkar and Ramadas (2011) designed a sequence of gesture-based instruction to teach students about elementary astronomy. The gestures were demonstrated and then repeated by the students in different orientations and circumstances, with the intention of helping them 'while observing the phenomenon to internalise it, or achieve 'ownership' of it, through their body configurations' (p.1721).

Gestures also transform material objects, and Roehl (2012) gives the example of a teacher who transforms a ball that has been projected horizontally, first into an 'epistemic object' through the use of gesture (tracing out the parabolic trajectory) and finally into a sign or representation on the blackboard, thus stripping the object of its materiality and singling out its semiotic significance within the disciplinary culture of science. This process is both familiar and essential in that pupils come to expect that material objects will be represented in this way as they progress through their scientific education. At the same time, learners themselves are transformed by the material practices of the classroom, engaging in material phenomena and resulting representations. Even the blackboard is highlighted as an important material presence throughout this process, acting as a kind of filter for what 'counts' as suitable interpretation of the phenomenon in question and reinterpreting what has been witnessed into a shared and immutable construct.

Interactive Whiteboards

The material presence of the board is brought into even sharper focus when interactive whiteboard (IWB) technology is used, with text, images and other media being physically manipulated by teachers and pupils touching the board. Research into the 
relationship between talk and IWB use in science lessons has been mainly based in primary schools. Murcia and Sheffield (2010) found that the degree of student participation in dialogue and the quality of student talk was higher in primary science lessons that made use of an IWB, and the teachers' use of open questions also increased after the IWB was introduced. What isn't clear is whether the physical interactivity made a difference or whether it was the teachers' altered pedagogical approach based on having access to multimedia resources. The authors correctly warn that any technology in the classroom is 'only as effective as the pedagogy that surrounds it' (Murcia and Sheffield, 2010, p.430). Mercer et. al (2010b) consider the possibility that an IWB creates a 'dialogic space' to promote children's collaborative reasoning, and the groups in their study that were using the IWB were more engaged than those who were using pen and paper materials. However, as a fixed object on the wall, the board was not equally accessible to all students, with taller pupils having greater access to the space, and only one group being able to work on it at a time. The IWB as a material presence thus opens up new ways of engaging with visual material and positioning bodies in relation to our representations of the world and has the potential to position learners as shapers rather than mere recorders of the learning that takes place.

Technology: physical and virtual materiality

While support for practical science is widespread, some researchers have stressed the inherent limitations of physical experiments, particularly the observation that learners often focus more on what they are doing than what they are learning (Osborne, 1998) and many advocate computer-based practical work as an alternative (e.g. Kirschner \& Huisman, 1998). In this line of argument, interactions with the material world are positioned as confusing, distracting and often superfluous to 
learning, except in cases where the aim is to develop specific perceptual-motor skills or engender tacit knowledge of tangible phenomena. Given the increasing emergence of digital simulations and virtual experiments, it is perfectly reasonable to ask, what is lost or gained in the move from material manipulation of physical artefacts to virtual manipulation in a computer-based environment?

Zacharia (2015) notes that the empirical research on the relative merits of physical manipulatives compared to virtual manipulatives in science is inconclusive, with some studies showing enhanced benefits from one or the other, and many indicating that they are equally effective for learning scientific concepts or that a blend of both is optimal. The research literature reveals a diverse array of educational purposes for which physical or virtual environments are variously preferred depending on the specific affordances they provide. For instance, Zacharia and de Jong (2014) found that students performing real experiments with electric circuits encountered process-related obstacles that restricted their development of conceptual models of current flow, while a virtual experimental set-up showing the current flow superimposed on the circuit led to superior conceptual understanding. In attempting to 'see' and understand current flow, a virtual simulation has obvious benefits for developing knowledge about the world, but this is achieved by removing the messiness of real objects and real data, arguably taking us further away from an embodied sense of being in the world.

Specifically questioning the necessity of touch-sensory or 'haptic' feedback from experimentation, studies comparing basic with haptic virtual manipulatives have also provided inconsistent outcomes. Based on results from several studies, Zacharia (2015) argues that while haptic sensory feedback from handling tangible objects is not always necessary for conceptual learning, 'touch sensory 
feedback is needed when the knowledge associated with it is incorrect or has not been constructed by the student through earlier physical experiences' (p.124). For example, Zacharia, Loizou, and Papaevripidou (2012) found that physicality, defined as 'the actual and active touch of concrete material and apparatus' (p.448), was a prerequisite for young children's learning about balance beams unless the child already had correct prior knowledge of how a balance beam works, in which case a virtual experiment was equally effective. Of the children who did not already understand balance beams, none of them managed to improve their understanding through the use of an equivalent virtual manipulative, without holding objects in their hands and placing them onto a real balance. This is a vitally important caveat, suggesting that at some point physical, sensory experiences are necessary and must come prior to the development of more abstract conceptual knowledge, though since the physical experience can be remembered it does not necessarily need to be repeated or present during the new phase of experimentation.

Triona and Klahr (2003) argue that 'point and click' should not be disregarded in favour of 'grab and heft' purely on the basis of constructivist theories and cultural traditions, yet many science educators struggle to let go of the idea of hands-on active experimentation. Zacharia and Olympiou (2011) conclude that it is the capacity for learners to manipulate a situation, whether physical or virtual that is the most important aspect of learning through science experimentation, and not touch sensory feedback per se. Similarly, Bumbacher, Salehi, Wieman, and Blikstein (2018) suggest that the nature of the manipulative environment used influences the kind of inquiry behaviours students engage in, and that this influence is determined by the specific affordances of the environment relative to the specific task and topic 'independent of whether they are physical or virtual' (p.215). Manipulation can therefore be seen as a form of dialogue 
between the learner and the phenomenon (real or simulated), a back and forth questioning of the material world. What differs between physical manipulatives and virtual manipulatives is the role the body plays in all this, what aspects of the material objects are deliberately omitted from the simulated version and how this shapes our relationship with the object(s) of our understanding.

Separating learners' bodies, the material world and the conceptual realm, postulated by constructivism, becomes even more difficult when considering mixed reality technologies and digitally enhanced physical experimentation. For instance Lindgren and Johnson-Glenberg (2013) describe several studies where learners control the movement of asteroids with their bodies or experiment with moving virtual objects up an inclined plane by waving a wand and observing the vector arrows overlaid on the simulation. Anastopoulou, Sharples, and Baber (2011) explored what happened when students in a physics class were given technology that could turn their own hand movements into instantaneous distance-time and velocity-time graphs. After physically manipulating the graphs through a sequence of movement activities and being asked to write a narrative account of each one, the group of 'doers' performed significantly better in a written test than a comparator group of 'watchers' who observed a teacher carrying out the activities and saw the resulting graphs. The researchers also observed that the 'doers' often experimented in a playful fashion, waving their hands and creating their own graphs, and suggest that this technology enabled a deeper relationship with and understanding of the abstract graphs as scientific representations of their own bodies. Furthermore, they suggest that 'when physical manipulation is interweaved with narration and self-evaluation, learners participate in a rhythmic cycle of engagement and reflection' (p.271), again suggestive of a dialogic process mediated by the motion tracker technology. 
As well as creating virtual or mixed reality versions of physical experiments, technology can also alter our relationship with the invisible and abstract entities that are often represented in model form as discussed earlier. The addition of haptic feedback to interactive visualizations, such as the nanoManipulator that allows students to 'feel' viruses at the nanometer scale using a haptic joystick (Jones, Minogue, Tretter, Negishi, \& Taylor, 2006), signals a further weakening of the distinction between mental and material interactions. Learners' enjoyment, engagement and understanding were all significantly improved when using haptic technology compared to a computer mouse. Moreover, students' discourse was found to be enhanced, with greater use of analogies, more questions generated and more affective terms used throughout the activity. Based on a similar study, Reiner (1999) suggests that a tactile interface acts as an agent in recruiting the embodied knowledge needed for learning formal physics concepts such as fields of force.

\section{Laboratory environment}

A laboratory or school science classroom is a very particular kind of space. The presence of glassware and other apparatus, often on display in glass cases, the benches and stools, sinks, electric sockets and gas taps, all indicate by way of the material world that this is a space for science. Although it precedes our search period, the classic study by Delamont, Beynon, and Atkinson (1988) is still widely cited in recent literature. They characterise students' first encounters with the secondary school science laboratory as rituals of initiation where they are introduced to artefacts imbued with special significance, like the ubiquitous Bunsen burner. Discourses of danger and safety give rise to rules governing the use of space and movement, while the manipulation of exotic objects and substances is what defines science as a discipline in the hierarchy of 
school subjects. As we will shortly show however, too often the role of the physical environment is discussed in terms of perceived (in)adequacy, and is under-theorised as a component part of the material fabric of scientific learning.

Studying the renovation of school science laboratories across Portugal, Veloso and Marques (2017) demonstrate that the design of laboratory space is both pedagogical and political. They point out that buildings are not just objects, but embody spatial relationships and social configurations, transmitting 'visual messages of how to feel and act' (p.227). Arzi (2003) shares this view that school laboratories are more than walls, benches and widgets' (p.595). For instance, a flexible space that combines laboratory benches with conventional classroom seating is considered to be more conducive to inquiry methods than a traditional laboratory design of the sort that dates back to the 19th century and was designed to facilitate the acquisition of routine technical skills. From an architect's point of view, Gisolfi (2006) suggests a range of questions that should be considered when deciding on something as simple as the layout of the desks or benches in a teaching laboratory, many of which are questions concerning what kind of talk is expected to take place within the space. Thus the material configuration of the laboratory, from the arrangement of desks to the positioning of gas taps and electric sockets, shapes and constrains the nature of the social and material interactions that are possible within it.

The material environment is only one strand of the widely used Science Laboratory Environment Inventory (SLEI) (Fraser, Giddings, \& McRobbie, 1995), along with student cohesiveness, rule clarity, integration and open-endedness, which serves as a reminder that the laboratory is a social space as much as a physical space. Nevertheless, students' perceptions of the material aspects of the laboratory environment have been shown to correlate with academic performance (Aladejana \& 
Aderibigbe, 2007) and attitudes to science (Fraser \& Lee, 2009; Lang, Wong, \& Fraser, 2005), while teachers' perceptions of the material environment are a significant indicator of job satisfaction (Halim, Che Ahmad, Syed Abdullah, \& Subahan Mohd Meerah, 2012). The limitation of such quantitative approaches to researching the material environment is that they provide information about perceived (in)adequacy of material spaces and resources, but not the nature of those spaces or how learners interact with them. Studies that include qualitative data to contextualise these findings reveal a more nuanced relationship. For example, Tsai (2003) found that Taiwanese teachers prioritised material resources more highly in their 'preferred' laboratory environment than any other factor. This was interpreted through interview data as a reflection of the teachers' epistemological beliefs about the purpose of laboratory work, specifically getting the required results to confirm specific scientific knowledge. Pupils meanwhile valued the student-cohesive, open-ended, integrated and rule-clear aspects of the laboratory environments more highly than their teachers. These distinct measures imply an artificial disconnect between the material and dialogic aspects of the teaching environment, with the emphasis on 'adequate' resources seeming to detract from considerations of how those materials might be integrated with the social dimensions of learning. Once again, our claim is that a clearer theoretical framing would assist, here by moving beyond judgements of (in)adequacy and towards an appreciation of how material context contributes to teaching and learning.

Finally there is insufficient space here to review the literature on the many ways that the physical environment can be enlisted when learning science beyond the laboratory: outdoors, through field work and in museums and science centres (Braund \& Reiss, 2004; Rennie, 2014), but the notion of the whole school as a 3-D textbook for environmental education is particularly appealing (Kong, Rao, Abdul-Rahman, \& 
Wang, 2014) and suggests that there are many as yet unexplored possibilities for integrating the material world into pedagogical practices in science.

\section{How is the role of 'the material' in Science Education currently understood?}

Some studies in science education are beginning to re/focus attention on the role of experience in science learning, with particular attention paid to embodied, sensory learning with respect to cognition. Roth and Jornet argue that the notion of experience is itself under theorised, and draw on Dewey, Vygotsky and Bakhtin to theorise experience as transactional and situated across space and time (Roth \& Jornet, 2014). The role of human bodily senses in interaction with materials is seen by Otrel-Cass (2018) as crucial to understanding how materials are part and parcel of learning science, but this is not simply about humans using inert materials: similarly to Roth and Jornet's transactional stance, she draws on Ingold (2011) and Roehl (2012), to consider materials as having processual and relational attributes, activated through teachers' and pupils' engagement with them, and argues for a 'body-mind pedagogy' that pays attention to the active role of the material as a result (Shusterman, 2012). Theories of embodied cognition, including sensorimotor theories, may offer a way of understanding the role of the senses in teaching and learning STEM subjects with associated implications for teaching and learning by exploring the relation between gesture and spatial thinking (Wesberg \& Newcombe, 2017), and how scientific concepts are represented and abstracted (Hayes \& Kraemer, 2017).

In part, this interest in embodied/material science learning has come about as a result of the introduction of new technologies in science classrooms, in exploring the way pupils interact with tablet and interactive whiteboard technology through talk and gesture (Kershner, Mercer, Warwick, \& Kleine Staarman, 2010; Sakr, Jewitt, \& Price, 2014). The relation between manipulation of materials, gesture and talk are used has 
been linked to teachers and pupils' representation of scientific ideas. Ibrahim-Didi et al. (2018) describe and theorise how bodily gesture and manipulation of materials are used by teachers and students in a multi-modal fashion as a dynamic form of representation of concepts in-the-moment. Multi-modality, with its focus on representation of phenomena in a range of physical and verbal ways, offers one way of exploring the interaction between the material and classroom talk (Kress, Jewitt, Ogborn, \& Charalampos, 2001). Recent work has explored how learners connect multiple representations in their interactions with the materials and each other (Jornet \& Roth, 2015) and the impact of such activity on learners understanding (Tytler, Prain, Hubber, \& Waldrip, 2013). This recent stream of research offers a fascinating and insightful perspective, but Tytler and colleagues are clear that this is an extension of constructivist learning theory. In line with consideration of models and pedagogical artefacts (see 2.2.1) there has been a theoretical shift away from seeing representations as correlated to scientific phenomena in as simple way, and towards recognizing the physical, artefactual nature of models, gestures, linguistic descriptions and visual representations in classrooms (Hardman, 2017). However, this shift has not (yet) been accompanied by leaving behind of constructivist framings of learning 'through activities', in favour of a more specific theorizing of the material intra-actions involved.

Constructivist accounts, even combined with artefactual views of models and representations, do not adequately theorise the way learners and teachers can think together with the material across these multiple modes of representation. It is still assumed that material objects and their behaviour must be represented in order to be understood. This move from material to abstract concept is critiqued by de Freitas and Palmer (2016), who draw on new materialist theory to argue that concepts, rather than requiring abstraction, are dynamic and relational, existing within material-discursive 
interactions. This critique has implications for pedagogy that go beyond arguing for attention to be paid to how pupils use materials, analysing embodied and sensory interaction. Our work in the second part of this paper is situated within this line of argument to theorise practical activity and classroom dialogue together in a relational sense. We will argue for a shift in emphasis during practical work towards teacher and pupils exploring the material-discursive science classroom together. This contributes to and extends the small, very recent, literature our review identified on the role of the material in STEM education.

\section{Theorizing the relationship between the material nature of science classrooms and classroom dialogue.}

Through literature review, we have shown that science is considered a practical subject by teachers, and that laboratories across the world condition the learning of the subject. Justifications for the use of practical work focus on the development of knowledge and skills, as well as understanding the processes of science. Motivation and creativity are also cited as important. However, the effectiveness of practical work towards these aims is far from established, and we contend that this is because there is not clear theoretical account of how pupils learn from such work, or what they learn.

Our review suggests that practical work is best defined when related to specific pedagogical strategies, in particular forms of questioning, argumentation and dialogic teaching. Here, Bakhtin's work provides a theoretical basis from which to understand the relational nature of dialogue, and the learning that takes place through it with a dialogic space. However, in relation to practical work in science, we identified a gap in theorizing dialogic relations with materials, both those under study in science, but also the broader material basis of laboratories. Work considering interactive whiteboards shows that dialogic theory is up to the task of supporting a broader understanding of 
dialogue however, as is Bahktin's theoretical frame. As such, existing work on dialogic teaching shows considerable promise in relation to science education for a number of reasons: firstly, it provides a specific account of interactions in classrooms and learning from them; secondly it is underpinned by a sound theoretical frame; thirdly, it is tried and tested in science education, through both qualitative and quantitative evaluation.

The second part of our literature review showed that practical inquiry work is not all that constitutes material in science laboratories however. Research into embodied cognition and the physical and virtual materiality manifest in technology, shows that the simple distinction between mind and matter is no longer possible. Learning and teaching involve bodies, gestures and materials. Constructivist accounts, with their focus on disembodied concepts, fail to adequately account for the material nature of classrooms and laboratories. Of note is the way that contemporary accounts of models and representations (such as diagrams) in science education have now shifted to recognizing the 'artefactual' nature of these materials in classrooms. Yet those that research these (e.g. Gilbert \& Justi, 2016; Tytler et al., 2013) try and maintain their framing as an extension of constructivism. We suggest that constructivism is actually stretched to breaking point by the move from concepts to the material as being at the heart of learning. This leads us to question, 'what happens if we think differently about the material nature of science education? What would change in how we approach science education if the material is reframed as an active participant in the learning taking place?

Of particular promise in relation to this is Karen Barad's (2007) theory of material-discursive Agential Realism. Barad's 'new materialist' work is beginning to have real theoretical purchase in bringing the role of the material to the fore in science education, demonstrated in its use in a number of articles in the edited volume 'Material 
Practice and Materiality: Too Long Ignored in Science Education' (Scantlebury \& Milne, In Press). As we will outline shortly, Barad's theory has a great deal of potential in understanding learning and teaching in science, as it provides a new account of the agency of matter in meaning making. Thus, in the remainder of this paper, we want to re(focus) attention on the materiality of school science. We will develop a theoretical framework to explore how pupils learn with the material, with the ultimate goal of considering the pedagogical implications of this shift in theoretical stance.

In this work, we use a relational ontology that draws on dialogic theory and Barad's theory of material-discursive Agential Realism. The reason for bringing these two theoretical frames together is that we believe them to be complimentary, but each contain an aspect of what is required to theorise learning and teaching within science education. We have argued that dialogic pedagogy has drawn effectively on dialogic theory to offer guidance for classroom practice. Bakhtin's dialogic concept was all about the embodiment of reason in actual voices, which had tone and emotion because they were part of real people in material contexts. He developed the idea of dialogic as a contrast to dialectic, which, he claimed, had become too abstract and removed from embodiment (Bakhtin, 1986, p147). Bakhtin did not limit the idea of voice and of a dialogue between voices to human bodies but famously wrote: 'I hear voices in everything, and dialogic relations among them' (Bakhtin, 1986, p169). However, despite the potential in Bakhtin's work for including the material, materiality has been largely left out of dialogic educational theory and its associated pedagogy. Barad's agential realism provides a new onto-epistemological frame for considering how meaning emerges through what she calls 'intra-actions'. This frame, like dialogic theory, provides and onto-epistemological position which is relational at its heart (as we will describe shortly). However, Barad's original work was focused on the study of 
professional science, rather than school science and, as of yet, Barad's frame has not been brought to bear directly on the pedagogical interactions / intra-actions in school laboratories. In bringing it together with dialogic teaching therefore we can say something about pedagogical relations that might not be immediately forthcoming from Barad's work alone.

In the rest of this paper therefore, we will outline a position which we have called a material-dialogic pedagogy (Hetherington \& Wegerif, 2018), showing how it meets the challenges and opportunities revealed through our literature review. To start, we briefly outline relevant elements from each theoretical strand before 'diffracting them through one another', to use Barad's terminology (see below) in order to articulate a how this frame might support understanding of the materiality of science education, and ultimately the pedagogies which support that education.

\section{Dialogic Education}

Dialogic education focuses on the important role of dialogue in learning, but is an umbrella term that may be used very simply to highlight the role of classroom talk for learning, through to expressing an ontological perspective on dialogic education. Thus, dialogic pedagogy may be about simply encouraging productive classroom talk; it may be used in an epistemological sense, focusing on constructing knowledge through engaging in dialogue (in which both verbal and non-verbal participate in the dialogue (Bakhtin, 1986)); and it may be ontological, in which engaging in dialogue is seen as inherently educational in that it produces changes in subjectivity (changing ourselves and our realities) (Wegerif, 2018). Here, we focus on dialogic in an ontoepistemological sense, drawing primarily on Wegerif's use of Bakhtinian dialogic theory, as it is this onto-epistemological understanding of dialogue that we find fruitful in synthesis with Barad's new materialist onto-epistemology. 
That dialogic education has a relational ontology is apparent when considering two key concepts: dialogic switching and dialogic space. Dialogic switching is the switch within a dialogue to see and feel as if from the perspective of an 'other'. Insights that arise as a result of dialogic switching are a product of the relationship: Without a relationship, it would not be possible to see things from different points of view and therefore the possibility of this kind of learning requires a dynamic relational ontology. Participants in the relationship may be physically embodied human voices but also cultural 'voices' or the voices of artefacts such as a computer interface (Kazak, Wegerif, \& Fujita, 2015). In the case of science education, we might refer to the 'voice' of the science practical materials, whiteboard, physical modelling materials and so on. In any case, knowledge is a phenomenon that emerges through dialogic interactions between these voices. Engaging in dialogic switching weakens identification with being on one side or other of the dialogic gap between voices and strengthens an identification with the gap itself or rather, another way of saying this, with the dynamic process of switching between positions to see things from multiple points of view. Dialogic switching is therefore both ontological and epistemological, producing knowledge whilst at the same time producing changes in the identity of the participants in the dialogue. An example of a dialogic switch that illustrates its relevance for education came in work in a science classroom video-recorded by Rich Lehrer and Leona Schauble. Two nine year old children were unable to agree on how to represent plant growth in a graph until one of them, using a physical gesture of inviting in, invoked the point of view of the future audience the graph. Switching from her point of view on the graph to see it afresh as if through the eyes of a future viewer enabled the children to understand better what it was that they were doing in drawing a graph (Wegerif, 2011b). According to Bakhtin understanding always takes this form of switching to see 
something as if from the outside, a move which is only possible within a dialogue, albeit often a dialogue with an absent projected cultural voice or 'superaddressee' position (Bakthin, 1986, p7 and p126).

Dialogic switching may be visible through both verbal and non-verbal utterances, gestures or other signification as the dialogue proceeds, but it can be theorised as occurring in a space of possibilities called dialogic space (Wegerif, 2011), where distinct voices are brought into relation with each other. Dialogic space is the space where new meaning emerges through interaction between voices who are changed by the interaction through the process of dialogic switching. Ultimately dialogic space is another way of thinking about the gap of difference between voices in a dialogue and giving that gap, 'the hinge around which voices turn', a role in understanding the generation of new meaning (Merleau-Ponty, 1968).

The relational onto-epistemological understanding of dialogic processes does allow for the non-human in dialogic interaction, but this perspective is not usually foregrounded in dialogic theory or the pedagogy associated with it. We suggest that Barad's material-discursive theory of agential realism extends a dialogic account of the production of meaning and the emergence of learning, as it foregrounds the 'voices' of the material. Since agential realism is not as familiar in the mainstream of educational research and practice as dialogic theory, we now turn to a more in depth (though still necessarily brief) explanation of the key ideas in agential realism.

\section{Barad's 'Material-discursive Agential Realism'}

Neither discursive practices nor material phenomena are ontologically or epistemologically prior. Neither can be explained in terms of the other. Neither is reducible to the other. Neither has privileged status in determining the other. Neither is articulated or articulable in the absence of the other; matter and meaning are mutually articulated (Barad 2007, p. 152). 
Barad (2007) defines her theory of 'material-discursive agential realism' as ontoepistemological, and she has developed clear terminology to describe and explain the theoretical concepts in a manner that hangs together as a coherent whole. This can make it challenging to explain any particular element of Barad's philosophy alone, and we suggest interested readers turn to her core work, 'Meeting the Universe Halfway' (Barad, 2007) to grapple with the ideas in greater depth. Here, we offer a necessarily short introduction to the key ideas we will use in developing our theoretical stance. Inspired by quantum physics (the discipline in which she holds a doctorate), in particular Niels Bohr's 'philosophy-physics' alongside the work of Michel Foucault, Donna Haraway, Judith Butler and others, Barad deploys a number of entwined ideas to develop a distinctive way of thinking about the 'naturalcultural' world and how we come to know with/in it, with a particular project to foreground the material. These ideas include the phenomena, intra-action, entanglement, diffraction, apparatus and the agential cut. Hers is a material feminist project that recasts science and scientific knowledge away from strong Cartesian dualities of knower/known, mind/body, nature/culture, and so on. It is not directly an educational project, but one in science studies that has been taken up within educational research, though surprisingly not strongly by science educators until recently, given its implications for thinking about the nature of science and Barad's own observation that the new understanding of the relationship between material phenomena and discursive practices she proposes 'has far-reaching consequences for grasping and attending to the political possibilities for change, the responsible practice of science, and the responsible education of scientists, among other important shifts' (Barad, 2007, p. 33).

At the heart of Barad's work are entanglements: 'To be entangled is not simply to be intertwined with another, as in the joining of separate entities, but to lack an 
independent, self-contained existence' (Barad, 2007, loc. 19). Everything is entangled, with matter and meaning always produced through relations not between pre-existing separate entities, but between phenomena that continually 'co-emerge through their simultaneous activity' (Rautio, 2013, p. 2). Barad uses the neologism intra-action rather than interaction, to highlight this entangled, co-emergent, co-productive relational stance. Similarly, instead of referring to 'objects' in the world, with determinate boundaries and properties, Barad's basic unit of reality is not the object but the phenomena, which are temporarily bounded and continuously performed through intraaction.

Agency is an important element in Barad's work. Within her relational ontology, matter is not given separate agency (a point of difference with Law and Latour's ActorNetwork Theory) but is an active participant in the performance of phenomena as part of intra-acting, entangled material-discursive practice. Both embodied humans and non-human materials have agency to produce phenomena (matter/meaning) intraactively by making 'agential cuts' that simultaneously close some possibilities whilst opening out others. Apparatuses are the means by which these agential cuts are enacted, and are thus boundary-making practices that specifically determine the production and performance of particular 'entities' within phenomena. For example, depending on the apparatus used, either the position or the momentum of a photon can be measured but not both at the same time (Barad, 2007, p. 113) - the apparatus is making an agential cut in its intra-action with the photon and the scientists to materialise and make meaningful the momentum or position of the photon. However, the concept of apparatus need not refer only to scientific apparatus, but more broadly to apparatuses as open-ended boundary producing practices that (re)-configure reality by enacting agential cuts. 
At this point, it might be useful to turn to a classroom-based example to demonstrate how the language of agential realism might apply to school science. We recently undertook an empirical study of an experienced teacher working with a class of 12-13 year olds, to understand the process of chromatography. Whilst we shall report more fully on this in future publications, here we will use this to exemplify how Barad's frame might allow new descriptions of a classic experiment: pupils dipping strips of filter paper into a mixture of ink and water, and observing as the inks separates into different components (according to solubility), as it travels up the paper. Whilst we could consider chromatography as the 'phenomenon' in question, this betrays a sense that chromatography is a universal, to be discovered by the minds of those who engage with it. Barad's use of the term phenomena takes us to an understanding of the specifics of the material circumstances, and here we might consider the 'phenomena' to be the meaning-making of the children in the classroom. This phenomena/meaning emerges from the intra-action of teacher and pupils with the experimental setup, with each other, and with the materials of the classrooms: whiteboards, textbooks, diagrams and verbal utterances. To exemplify how this entanglement leads to the phenomena of meaningmaking, consider a difficulty that some of the pupils had. They concluded, that the 'darker colours' travelled further up the chromatography paper. This is not scientifically accurate, as it is the solubility and not the colour of the ink which influences how far it travels up the paper. In Barad's terms though, the ink itself, the particular felt-tip pen used by those students contributes to the enacting agency; there is an agential cut as the mobile ink makes some understandings possible whilst restricting others (e.g. that the light colours travel further). The 'apparatus' however, should not be seen as the equipment and liquids alone. It is the pupils who recognise and name colours, and judge blue to be 'darker' than red for example. The electromagnetic 
spectrum is a continuum, and as such judgements and labels of colour lie within the social sphere. The apparatus therefore includes the understandings of pupils, based on interpretations of colour, but also perhaps on some sense that colour is important in chemistry. Thus, we might understand the 'misconception' that pupils derive as a phenomenon born of the entangled agency of the experimental material and the apparatus through which they are viewed, including the linguistic and social understandings of the pupils. Whilst this is a short example, we hope it illustrates the potential of Barad's terminology to say something new about school science.

A final important concept in agential realism is that of diffraction (Barad, 2014), which might be ascribed less to consideration of situations themselves, and more as a methodological consideration. The term diffraction denotes a process of cutting together-apart, where intra-acting material-discursive phenomena are brought together and diffracted through one another, producing new matter/meaning. Following Donna Haraway (1997) in moving away from the optical metaphor of reflection which relates to representational thought and Cartesian dualism, Barad is inspired by the phenomenon of diffraction, in which waves (and in fact particles, in what is described as a 'quantum weirdness') produce diffraction patterns of ripples, peaks, troughs, light spots and dark spots as they pass through a diffraction grating or obstacle - as they intra-act with and produce difference. Barad's diffractive method is not to be taken as a literal application of physical diffraction, but she is 'interested in building diffraction apparatuses in order to study the entangled effects differences make' (Barad, 2007, p. 73) within a performative rather than a representational mode, recalling that apparatus does not necessarily refer to physical, scientific apparatus. Thus, she advocates reading theoretical insights through one another, mobilising her concepts of the agential cut and 
agential separability in cutting together-apart, intra-acting different entangled matter/meanings and exploring the effects.

As was outlined at the start of this section, bringing Barad's frame together with dialogic theory has the potential to provide an account of pedagogical relations, which draws upon the established nature of the latter in science education. In the final part of this paper, then, we follow Barad's inspiration and diffract dialogic theory and agential realism through one another, cutting them together-apart to generate a material-dialogic theoretical framework that might have purchase to guide a consequent material-dialogic pedagogy for science education.

\section{Material-Dialogic: A diffractive reading}

Before we proceed, we should note specifically that our aim is not to synthesise the different theoretical perspectives from the outside in order to offer a prescription for practice, but to intra-act with/in them, to 'experiment with...differences, getting a feel for how they are produced and how they matter' (Karen Barad, in interview with Adam Kleinman, 2012, p. 77). We are intra-acting with them, enacting specific agential cuts, highlighting particular differences and becoming entangled with them in particular ways to materialise ideas with which other researchers and teachers may intra-act and cut together-apart with their research and pedagogical practices as part of a lively, dynamic and creative process.

\section{Relational Intra-action in a material-dialogic space}

A dialogic space is a space of relation between different voices, where both meaning and subjectivities emerge in the relation. The term 'voice' gives primacy to the discursive element of those engaging in the relationship, but agential realism draws the 
material much more closely into the entangled relationships within a dialogic space. Using Barad's language, phenomena, the temporarily bounded entities intra-acting relationally to produce those phenomena through agential cuts, and the meaning of material-discursive concepts relating to the phenomena, come into being in the intraactions. Phenomena (including but not limited to scientific phenomena), 'voices', 'bodies', meaning and matter all continually come into being together within a relational space.

This is different to the more usual understanding of dialogic space for two reasons. Firstly, because the distinct voices in the dialogue do not pre-exist, but come into being through the intra-action within the relational space. The boundaries between the voices, the 'othering' emerges through the intra-action. Without this 'othering', this agential separability in agential realist theory, there can be no intra-action since, as Bakhtin argues, without difference there can be no dialogue. Secondly, the relational space of intra-action (not interaction) is material, not a conceptual space of disembodied ideas. The space is thus both material and discursive together, which we find useful to label as 'material-dialogic' space in which there is potential meaning to be actualised materialised, even - depending on the relations in that space.

To explain the difference in this move from dialogic to material-dialogic space, it is useful to think through a classroom example. In their study of the use of interactive whiteboards (IWB) in collaborative learning in Primary Science, Neil Mercer and colleagues analysed a group of 9-10 year old children using an IWB to explore how the Gruffalo (from Julia Donaldson and Axel Scheffler's famous children's story) is adapted to its habitat. The study used detailed recording and transcription of pupils' work at the IWB, with data presented primarily as sections of dialogue in one column, description of some gestures or use of the board pen at the correct point within the dialogue in a 
second column, and the material environment explained before or after the extracts as context to the dialogue (Mercer et. al, 2010b). In their analysis, there are several points of note that demonstrate the importance of bodies and the material in the learning taking place. For example, the authors note the influence on the dialogue of the fact that only the taller boy is able to manipulate some of the buttons on the IWB. In the presentation of the data in this paper, the transcription shows the dialogue between pupils in one column, and their interaction with the whiteboard and the rest of their classroom environment or physically with each other in a second column, noting, for example, where a child, Leonie, reads questions pinned by the teacher to the wall, or points to previous writing on the whiteboard, gives and takes the pen, and later rewrites a word. It is clear from the analysis in their paper that Mercer and colleagues consider the materiality of the IWB, the classroom environment and the pupils' bodies to be important, making a difference to the dialogic space. Indeed, they note that the IWB offers an augmentation of dialogic space as it 'keeps children's work held in relation to each others previous utterances (written on the board) in a way that sustains and deepens reflection on the concepts and the play of ideas' (Wegerif, pers. Comm., in Mercer et al, 2010b). However, the authors do not attempt to explicitly theorise this material role, whilst recognizing its importance.

The material-dialogic space we propose in this paper offers such a theory as a means to further foreground the role of such embodied, material aspects of the classroom, bringing it directly into the dialogic theory and moving it beyond an 'augmentation of the space' to an active 'voice' within the space. It goes beyond simply adding the material into the dialogue, as something with which the pupils interact, and bring out the role of the material in intra-acting agency. Thus, voices in the dialogue are created intra-actively and need not solely belong to only the children in the analysis. 
Instead, our proposed framework allows us to think about the voice of the group of children, or child-child-pen assemblages, or teacher-board assemblages. This is useful because we can see how the learning takes place as a result of the relations between individuals and materials, but also how it might be affected by relations between groups of both human and other-than-human. So here, we could examine the influence of the teacher-board on the learning taking place, to think about how children are in an educational relationship with the teacher and whiteboard together - the teacher is not currently directly interacting with them, but in setting up the board, the teacher and board together interact with the children in a material-dialogic space, prompting them to think and rethink about habitats in new ways they have not previously considered.

\section{Diffractive Switching}

Barad's concept of diffraction has some points of similarity with the idea of dialogic switching, where difference-in-relation is necessary to create new understandings that change those involved in the dialogue. We suggest that although Barad's use of diffraction in her work is primarily a methodological and analytical approach to interdisciplinary studies, it can be read together with the concepts of intra-activity and dialogic switching, to offer guidance for pedagogy that draws together both the classroom material and classroom dialogue.

To be able to intra-act, there must be boundaries objects participating in the intra-action, but in contrast with interaction, the objects do not pre-exist their relation but are produced through it. Therefore, a new materialist ontology leads us to reexamine the concept of the dialogic switch within Bakhtin's dialogic theory. Dialogic switching between voices is the means by which dialogue can proceed - the 'switch', to seeing from a different perspective, is crucial in a continuing dialogue as it allows the relation, the intra-action, between different perspectives. Without a dialogic switch there 
can be no relation, but without different perspectives there can be no dialogue as there is only agreement (Bakhtin, 1986). However, the dialogic switch requires voices of 'others' to be brought into relation that, as in an interaction, are pre-existing entities. How can a dialogic switch proceed in a material-discursive intra-action, rather than an interaction? Barad's diffraction, like the dialogic switch, is also concerned with the bringing together of differences in relation, by cutting them together-apart to produce matter and meaning in the emergence of new phenomena. Diffraction performs this switching move by intra-acting differences through one another, explicitly drawing in the non-human 'voices' involved in the intra-action. We can label this intra-active understanding of the switch between participants in the intra-action as a diffractive switch, which we find useful to further explain and understand Barad's notion of cutting together-apart. In diffractive switching, continuously produced, boundaried, materialdiscursive phenomena need to switch perspectives to be able to intra-act. This is the cutting-together. At the same time, as part of the same process, they are intra-acting within a material-dialogic space and, through the intra-action, are separated and boundaried, or cut apart. Taking again the example of the pupils' work with an interactive whiteboard to think about the kind of habitat a Gruffalo might be adapted to live in (Mercer et al. 2010b). The pupils are given a series of possible habitats which they can scroll through on the whiteboard, to select and annotate. We can identify in the pupils' dialogue where they begin by disagreeing about the habitat, and, through dialogue, reach a point of agreement. From a material-dialogic perspective, we can go beyond this to think about the shifting boundaried intra-acting assemblages and how they perform a diffractive switch manoeuver from which new thinking can emerge. So, rather than the whiteboard being a tool that is context for the dialogue, it is brought directly into the dialogue. For example, Gordon-Whiteboard selects a grassland habitat, 
which Leonie-May disagrees with, then a new intra-active assemblage of Leonie-MayWhiteboard selects Woodlands, followed by May-Pen beginning to write. Throughout this, their spoken dialogue is linked to their physical intra-action with the material, as the assemblages dissolve and reform, switching between different perspectives until a consensus is reached. This analysis foregrounds the way the board, offering series of options, could be seen as part of an agentic intra-action: it pushes its way forward into the learning taking place as part of the dialogue.

In a similar way, a practical science activity such as studying a chemical reaction or process, the notion of a diffractive switch highlights in particular the way the intra-acting materials have a 'voice' in the creation of meaning: the bench, recording materials, glassware, reacting chemicals, chemicals produced, recording equipment, sounds, smells and so on as equally important in the dialogue as the pupils' and teachers voicing their ideas and the disciplinary knowledge on which they draw in the materialdialogic space. That is not to say that the teachers and pupils must deliberatively 'switch' to consider the 'point of view' of the reacting chemicals. For students to be able to learn from practical work matter needs to move from being background context to being a voice in a dialogue, a voice that means something, that makes a difference. This tends to happens when practical inquiry answers questions that the students have already posed both verbally and tacitly (Kazak et al., 2015). Diffractive switching is about drawing the voices of the material into the dialogic space (or how they push their way in, for example how the colours of a chromatograph influence meaning-making), to explore how they relate to the dialogue as points of difference that material-discursively perform new phenomena (learning) with the pupils and teachers engaged in the dialogue. 


\section{Material-dialogic Pedagogy}

This diffractive reading of Bakhtinian dialogic theory and Agential Realism raises questions of pedagogy. What does the new theoretical framework generated suggest one does differently with respect to teaching science?

Firstly, this framework enables us to understand pedagogy in a particular way, as a material-dialogic practice in which planning, teaching, reading, talking with teacher and pupils, practical activity and so on all intra-act to enact agential cuts in materialdialogic space, producing phenomena, subjectivities and meaning. This is useful for thinking about education. Dialogic pedagogy rests on the idea that knowledge is produced through dialogue, with concepts such as the dialogic switch and dialogic space brought to bear to develop teaching and learning approaches. Drawing on new materialism through Barad's work, learning can be seen as a phenomenon in which matter and meaning are made through continuous intra-activity. In the science classroom, a material-dialogic framework tunes us in to thinking of teachers, pupils, practical materials, classroom tools, models and artefacts as entangled intra-acting phenomena that are continuously produced within a material-dialogic educational space. Diffractive switching helps us tune in to the voice of the practical materials (or bodies, gestures, textbook, desk or pen or smell of reacting chemicals, or any other temporarily boundaried intra-acting assemblage) as 'others', with voices in the dialogue. Thinking in this way, and encouraging teachers to do so (Hetherington \& Wegerif, 2018), encourages science teachers to focus more closely on how the material (including but not limited to practical materials) plays in to pupils' learning.

Secondly, this framework helps us think specifically about the material nature of practical work. For example, in the empirical study from which we draw the earlier example of chromatography, initial analysis suggests that the teacher is continually 
engaged with materials and implicitly recognise their importance, but does not fully rationalise this agency of the material. Research suggests that planning for practical work appears to have a tendency to be primarily logistical or focused on a key misconception or skill, with less attention given to planning how to use the practical activity to foster learning (Abrahams \& Millar, 2008). A material-dialogic pedagogy drives towards a focus on how materials, including practical activities, are in dialogue with teachers and pupils to produce new learning.

In reconsidering the reported aims of practical work within our literature review, we see that the development of disciplinary understanding involves intra-action of pupil thinking, discussion and embodied action with materials, models, representations and products of practical investigations. The theoretical framework proposed refutes the ontological priority of any of these in the phenomena of learning, and as such forces teachers to focus on these intra-actions. Engagement and the exemplification of creative processes were also primary concerns for teachers, and this can only be heightened by teachers recognizing that learning is an emergent and dynamic process performed through agentic intra-action with embodied teachers, learners and materials. Using this material-dialogic theoretical framework suggests a pedagogical approach in which the concept of 'diffractive switching' requires that teachers and pupils together read insights from practical activities (materials), pedagogical tools such as worksheets and textbooks (semiotic materials) and dialogue simultaneously to illuminate differences in thinking and new ideas as they emerge. In the same way that dialogic pedagogy prompts specific ways of working that foster exploratory talk, (using collaborative activity, avoiding an 'initiation-response-feedback' (IRF) pattern of teacher talk, or using question prompts for example), a material-dialogic pedagogy builds on these but deliberatively draws in the material. Teachers employing a material- 
dialogic pedagogy would purposefully break away from a linear sequence of practical work, observation, discussion and conclusion and instead consider other lesson structures. This would allow the embedding and exemplification of the dynamic processes of science so valued by science educators. Examples of pedagogic strategies towards this might include: pausing a practical activity to ask questions that prompt dialogue, using prompt questions during dialogues that direct pupils' attention to materials, pausing dialogues to look for insights from other sources, and 'bouncing' the material 'voices' in to a whole-class dialogue when moving away from IRF dialogue patterns towards something like 'Initiation, Pupil Response, Pupil Response, Material Insight, Pupil Response, Pupil Response...'. These suggestions are, of course, as yet untested and are theoretically inspired rather than empirically evidenced. In the next section we discuss what, if any, recommendations can be made on the basis of the framework laid out in this paper.

\section{Recommendations}

The literature on the use of practical work in science says much about teachers' perspectives on the purpose of practical activities in science for disciplinary learning, skills development, and the motivation of pupils. However, the extent to which it is used effectively has been drawn into question. We have proposed that this is because the intra-action of dialogue and material is under theorised within practical science activities. Furthermore, a growing body of literature focusing upon embodied cognition, gesture, models, representations and physical laboratory environments are drawing attention to the need for a greater appreciation of the agency of matter in science education, both including and beyond practical inquiry work.

Developing effective dialogue around practical activities has been advocated as one way of improving the impact of practical work on pupils' learning (Mercer et al, 
2004), and studies suggest that effective questioning in relation to practical activities can be helpful in doing this (Chin, 2006). However, discussion of dialogic pedagogies in science education to date have not adequately accounted for the agency of matter. As we have shown, Bakhtinian theory, on which much of dialogic theory is based, is up to the task of supporting a great focus upon relations with matter, as well as people, involved in meaning-making. At present however, the focus of dialogic pedagogy upon the verbal and linguistic provides little advice to teachers about the material nature of science education, and how to recognise that in supporting learning. We have attempted to begin the process of addressing this by developing a theoretical account of how the material is part of the dialogue by which learning proceeds. In doing so, we make a case for a material-dialogic pedagogy in science education.

However, further research is required before well-founded recommendations for practice can be made: this paper develops a theoretical foundation on which an associated pedagogy can be built. Empirical classroom research is required to examine material-discursive intra-action with respect to learning science. Such work will better define how learning and teaching are entangled with matter. Although a detailed analysis is currently being undertaken, initial coding of a detailed video study exploring practical teaching of a sequence of lessons on chromatography (article in prep) suggests that a large proportion of time was spent intra-acting in dialogues with reference to material resources: mini-whiteboards, pens and ink, experimental equipment, but that this was not a focus of the teachers' planning or evaluation of the lesson. Mercer et. al's (2010a) study of interactive whiteboards as a dialogic space offers some insight into the relation between material and dialogue that will be of use in developing further research. Analysis of the role the material is given, both implicitly and explicitly within existing practice both with practical work and with other materials, including interactive 
whiteboards, will be important in developing pedagogical recommendations using the framework for material-dialogic pedagogy developed in this paper. Research to test the impact of such an approach in practice would then be required before the suggestions in section 3 can be offered as secure guidance for teachers' practice.

\section{Conclusion}

Science should be understood as long term dialogue with nature in which nature is not simply inert and meaningless but plays an active role in biting back against the interpretations imposed upon it. Few scientists would deny the importance of the material world in science, and this means that few science educators question the importance of engaging with materials in the classroom, be they experimental equipment and subjects, models, diagrams and virtual learning environments. Yet there is a difference between the way that science develops understandings about the world, and the way that students learn about science. For the last few decades the dominance of constructivist and social constructivist accounts of learning have masked the role of the material in learning, through focusing upon intangible and disembodied concepts as the site of learning. As such, the role of the material in science education has remained under-theorised, and the mixed evidence around the effectiveness of practical work in supporting learning has, we suggest, been at least in part to do with the lack of a theoretical basis from which to consider specific pedagogical approaches in science.

In proposing a material-dialogic approach to science education, we have drawn on dialogic theory, which is tried and tested in science education, and offers both a theoretical basis and specific account of pedagogies equal to understanding dialogue between both people and matter in science laboratories. However, it is through the diffracting of dialogic theory with Barad's agential realism that the agency of matter is fully recognised, and the entanglement of meaning and matter is apparent in defining 
the apparatus and phenomena through which learning and teaching takes place. We have demonstrated this shift in thinking with reference to practice through re-examining published work into children's dialogue through an interactive whiteboard, by exploring a practical example of chromatography, and by offering further ideas and examples typical of secondary science practice. We suggest that foregrounding the material as part of the dialogue of the science classroom (in particular the way it is part of, and intra-acts with, shifting assemblages) to create new matter and meaning, suggests alternative guidance for science teaching practice. This theory-driven guidance would builds on the acknowledged strengths of dialogic pedagogy whilst being explicit about the role of the material in science education, not least with respect to effective practical work. Thus, the material-dialogic framework we propose, with its concepts of diffractive switching and material-dialogic space, has the potential to frame a pedagogical practice that inducts students into the dialogue with nature that is at the heart of science, whilst also drawing attention to the dialogue with matter in school laboratories that is at the heart of meaning-making in science education.

\section{References}

Abrahams, I. (2011). What does research say about the nature and purpose of practical work? Education in Science 244, 28-29.

Abrahams, I., \& Millar, R. (2008). Does Practical Work Really Work? A study of the effectiveness of practical work as a teaching and learning method in school science. International Journal of Science Education, 30(14), 1945-1969.

Abrahams, I., \& Reiss, M. J. (2012). Practical work: Its effectiveness in primary and secondary schools in England. Journal of Research in Science Teaching, 49(8), 1035-1055.

Abrahams, I., Reiss, M. J., \& Sharpe, R. M. (2013). The assessment of practical work in school science. Studies in Science Education, 49(2), 209-251.

Abrahams, I., Reiss, M. J., \& Sharpe, R. M. (2014). The impact of the 'Getting Practical: Improving Practical Work in Science' continuing professional 
development programme on teachers' ideas and practice in science practical work. Research in Science \& Technological Education, 32(3), 263-280.

Abrahams, I., \& Saglam, M. (2010). A Study of Teachers' Views on Practical Work in Secondary Schools in England and Wales. International Journal of Science Education, 32(6), 753-768.

Abrahams, I., \& Sharpe, R. M. (2010). Untangling what teachers mean by the motivational value of practical work. School Science Review, 92(339), 111-115.

Aladejana, F., \& Aderibigbe, O. (2007). Science laboratory environment and academic performance. Journal of Science Education and Technology, 16(6), 500-506.

Alsop, S. (2011). The body bites back! Cultural Studies of Science Education, 6(3), $611-623$.

Andersson, J., \& Enghan, M. (2017). The relation between students' communicative moves during laboratory work in physics and the outcomes of their actions. International Journal of Science Education, 39(2), 158-180.

Anastopoulou, S., Sharples, M., \& Baber, C. (2011). An evaluation of multimodal interactions with technology while learning science concepts. British Journal of Educational Technology, 42(2), 266-290.

Arzi, H. (2003). Enhancing science education laboratory environment: More than wall, benches and widgets. In B. J. Fraser \& K. Tobin (Eds.), International Handbook of Science Education (pp. 595-608). Netherlands: Kluwer Academic Publishers

Bakhtin, M. (1986). Speech genres and other late essays (V. W. McGee, Trans.). Austin, TX: University of Texas Press.

Barad, K. (2007). Meeting the Universe Half-way: Quantum Physics and the Entanglement of Matter and Meaning. Durham: Duke University Press.

Barad, K. (2014). Diffracting Diffraction: Cutting Together-Apart. parallax, 20(3), 168187.

Berry, A., Mulhall, P., Gunstone, R., \& Loughran, J. (1999). Helping students learn from laboratory work. Australian Science Teachers Journal, 45(1), 27-31.

Braund, M., \& Reiss, M. (Eds.). (2004). Learning science outside the classroom. London: RoutledgeFalmer.

Bryce, T. G. K., \& Blown, E. J. (2016). Manipulating models and grasping the ideas they represent. Science and Education, 25, 47-93. 
Bumbacher, E., Salehi, S., Wieman, C., \& Blikstein, P. (2018). Tools for science inquiry learning: Tool affordances, experimentation strategies, and conceptual understanding. Journal of Science Education and Technology, 27(3), 215-235.

Cheung, D., \& Yip, D-Y. (2004). How science teachers' concerns about school-based assessment of practical work vary with time: the Hong Kong experience. Research in Science \& Technological Education, 22(2), 153-169.

Chin, C. (2006). Classroom Interaction in Science: Teacher questioning and feedback to students' responses. International Journal of Science Education, 28(11), 13151346.

Chin, C. (2007). Teacher Questioning in Science Classrooms: Approaches that Stimulate Productive Thinking. Journal of Research in Science Teaching, 44(6), 815-843.

Çımer, Atilla. (2007). Effective Teaching in Science: A Review of Literature. Journal of Turkish Science Education (TUSED), 4(1), 20-44.

Clough, M. P. (2002). Using the Laboratory to Enhance Student Learning. In R. W. Bybee (Ed.), Learning Science and the Science of Learning Washington, DC: National Science Teachers Association

Coll, R. K., France, B., \& Taylor, I. (2005). The role of models/and analogies in science education: Implications from research. International Journal of Science Education, 27(2), 183-198.

Coole, D. \& Frost, S. (2010). New Materialisms: Ontology, Agency and Politics. Durham \& London: Duke University Press.

Cowie, B, Otrel-Cass, K, \& Moreland, J. (2015). The materiality of materials and artefacts used in science classrooms. Paper presented at the American Educational Research Association Annual Conference 2015, Chicago, IL.

Delamont, S., Beynon, J., \& Atkinson, P. (1988). In the beginning was the Bunsen: The foundations of secondary school science. International Journal of Qualitative Studies in Education, 1(4), 315-328.

DeFreitas, E., \& Palmer, A. (2016). How scientific concepts come to matter in early childhood curriculum: rethinking the concept of force. Cultural Studies of Science Education, 11(4), 1201-1222.

DeWitt, J., Archer, L., \& Mau, A. (2016). Dimensions of science capital: exploring its potential for understanding students' science participation. International Journal of Science Education, 38(16), 2431-2449. 
Dikmenli, M. (2009). Biology student teachers' ideas about purpose of laboratory work. Asia-Pacific Forum on Science Learning \& Teaching, 10(2), 1-14.

Donnelly, D., O'Reilly, J., \& McGarr, O. (2013). Enhancing the Student Experiment Experience: Visible Scientific Inquiry Through a Virtual Chemistry Laboratory. Research in Science Education, 43(4), 1571-1592.

Ferreira, S., \& Morais, A.. (2014). Conceptual Demand of Practical Work in Science Curricula. Research in Science Education, 44(1), 53-80.

Fox, N. J., \& Alldred, P. (2016). Sociology and the New Materialism: Theory, Research, Action. London: SAGE.

Fraser, B. J., Giddings, G. J., \& McRobbie, C. J. (1995). Evolution and validation of a personal form of an instrument for assessing science laboratory classroom environments. Journal of Research in Science Teaching, 32(4), 399-422.

Fraser, B. J., \& Lee, S. S. U. (2009). Science laboratory classroom environments in Korean high schools. Learning Environments Research, 12(1), 67-84.

Frejd, J. (2018). "If it lived here, it would die." Children's use of materials as semiotic resources in group discussions about evolution. Journal of Research in Childhood Education, 32(3), 251-267.

Gilbert, J. K., \& Justi, R. (2016). Approaches to Modelling-Based Teaching. In J. K. Gilbert \& R. Justi, Modelling-based Teaching in Science Education (Vol. 9, pp. 57-80). Switzerland: Springer International Publishing.

Gisolfi, P. A. (2006). Spaces for teaching science. American School Board Journal, (April), 60-63.

Gott, R., \& Duggan, S. (2007). A framework for practical work in science and scientific literacy through argumentation. Research in Science \& Technological Education, 25(3), 271-291.

Gough, Noel (1998). 'If this were played upon a stage...': School laboratory work as a theatre of representation. In J. Wellington (Ed.), Practical Work in School Science: Which Way Now? (pp.69-89). London: Routledge.

Haigh, M. (2007). Can Investigative Practical Work in High School Biology Foster Creativity? Research in Science Education, 37(2),

Halim, L., Che Ahmad, C. N., Syed Abdullah, S. I. S., \& Subahan Mohd Meerah, T. (2012). Teachers' perception of science laboratory learning environment and its relationship to teachers' satisfaction. International Journal of Learning, 18(8), $67-78$. 
Haraway, D. (1997). The Promises of Monsters: A Regenerative Politics for Inappropriate/d Others. In L. Grossberg, C. Nelson \& P. Treichler (Eds.), Cultural Studies (pp. 295-337). New York: Routledge.

Hardman, M. A. (2017). Models, matter and truth in doing and learning science. School Science Review, 98(365), 91-98.

Harlen, W. (2013). Inquiry-based learning in science and mathematics. Review of Science Mathematics \& ICT Education, 7(2), 9-33.

Harrison, A. G., \& Treagust, D. F. (2000). A typology of school science models. International Journal of Science Education, 22(9), 1011-1026.

Hart, C., Mulhall, P., Berry, A., Loughran, J., \& Gunstone, R. (2000). What is the Purpose of this Experiment? Or Can Students Learn Something from Doing Experiments? Journal of Research in Science Teaching, 37(7), 655-675.

Haslam, C. Y., \& Hamilton, R. J. (2010). Investigating the Use of Integrated Instructions to Reduce the Cognitive Load Associated with Doing Practical Work in Secondary School Science. International Journal of Science Education, 32(13), 1715-1737.

Hayes, J., \& Kraemer, D. J. M. (2017). Grounded Understanding Of Abstract Concepts: the case of STEM learning. Cognitive Research: Principles and Implications, 2(7).

Helliar, A.T., \& Harrison, T. G. (2011). A Wider Role For Technicians In Science Practical Work With School Students? Acta Didactica Napocensia, 4(4), 1-10.

Hetherington, L., \& Wegerif, R. (2018). Developing a material-dialogic approach to pedagogy to guide science teacher education. Journal of Education for Teaching, 44(1), 27-43.

Hodson, D. (1993) Re-thinking Old Ways: Towards A More Critical Approach To Practical Work In School Science, Studies in Science Education, 22(1), 85-142. Hodson, D. (2014). Learning Science, Learning about Science, Doing Science: Different goals demand different learning methods. International Journal of Science Education, 36(15), 2534-2553.

Hofstein, A., \& Lunetta, V. N. (1982). The role of the laboratory in Science Teaching: Neglected aspects of research. Review of Educational Research, 52(2), 201-217. Hofstein, A., \& Lunetta, V. N. (2004). The Laboratory in Science Education: Foundations for the Twenty-First Century. Science Education, 88(1), 28-54. 
Hofstein, A., Lunetta, V. N., \& Clough, M. P. (2007). Learning and Teaching in the School Science Laboratory: An Analysis of Reserch, Theory and Practice. In S. K. Abell \& N. G. Lederman (Eds.), Handbook of Research on Science Education (pp. 393-433). Mahwah, NJ: Lawrence Erlbaum Associates. Högström, P., Ottander, C., \& Benckert, S. (2010). Lab Work and Learning in Secondary School Chemistry: The Importance of Teacher and Student Interaction. Research in Science Education, 40(4), 505-523.

Ibrahim-Didi, K., Hackling, M. W., Ramseger, J., \& Sherriff, B. (2018). Embodied Strategies in the Teaching and Learning of Science. Quality Teaching in Primary Science Education, 181-221.

Ingold, T. (2011). Being Alive: Essays on Movement, Knowledge and Description. London: Routledge.

Itzek-Greulich, H., \& Vollmer, C. (2017). Emotional and motivational outcomes of lab work in the secondary intermediate track: The contribution of a science center outreach lab. Journal of Research in Science Teaching, 54(1), 3-28.

Jay, T., Willis, B., Thomas, P., Taylor, R., Moore, N., Burnett, C., . . Stevens, A. (2017). Dialogic Teaching: Evaluation report and executive summary. London: Education Endowment Foundation.

Jenkins, E. W. (2000). Constructivism in School Science Education: Powerful Model or the Most Dangerous Intellectual Tendency? Science \& Education, 9(6), 599610.

Jones, M. G., Minogue, J., Tretter, T. R., Negishi, A., \& Taylor, R. (2006). Haptic augmentation of science instruction: Does touch matter? Science Education, 90(1), 111-123.

Jornet, A., \& Roth, W.-M. (2015). The joint work of connecting multiple (re)presentations in science classrooms. Science Education, 99(2), 378-403.

Kapenda, H. M., Kandjeo-Marenga, H. U., Kasandra, C. D., \& Lubben, F. (2002). Characteristics of Practical Work in Science Classrooms in Namibia. Research in Science \& Technological Education, 20(1), 53-65.

Kazak, S., Wegerif, R., \& Fujita, T. (2015). The importance of dialogic processes to conceptual development in mathematics. Educational Studies in Mathematics, 90(2), 105-120.

Kershner, R., Mercer, N., Warwick, P., \& Kleine Staarman, J. (2010). Can the interactive whiteboard support young children's collaborative communication 
and thinking in classroom science activities? International Journal of ComputerSupported Collaborative Learning, 5(4), 359-383.

Kind, P. M., Kind, V., Hofstein, A., \& Wilson, J. (2011). Peer Argumentation in the School Science Laboratory-Exploring effects of task features. International Journal of Science Education, 33(18).

Kirschner, P., \& Huisman, W. (1998). 'Dry laboratories' in science education; computer-based practical work. International Journal of Science Education, 20(6), 665-682.

Kirschner, P. A., Sweller, J., \& Clark, R. E. (2006). Why Minimal Guidance During Instruction Does Not Work: An Analysis of the Failure of Constructivist, Discovery, Problem-Based, Experiential, and Inquiry-Based Teaching. Educational Psychologist, 41(2), 75-86.

Kong, S. Y., Rao, S. P., Abdul-Rahman, H., \& Wang, C. (2014). School as 3-D textbook for environmental education: Design model transforming physical environment to knowledge transmission instrument. Asia-Pacific Education Researcher, 23(1), 1-15.

Kress, G., Jewitt, C., Ogborn, J., \& Charalampos, T. (2001). Multimodal Teaching and Learning: The Rhetorics of the Science Classroom. London: Continuum.

Lang, Q. C., Wong, A. F. L., \& Fraser, B. J. (2005). Student perceptions of chemistry laboratory learning environments, student-teacher interactions and attitudes in secondary school gifted education classes in Singapore. Research in Science Education, 35(2-3), 299-321.

Lazarowitz, R., \& Tamir, P. (1994). Research on Using Laboratory Instruction in Science. In D. Gabel (Ed.), Handbook of Research in Science Teaching and Learning. (pp. 94-128). New York: Macmillan.

Lawrence, C., \& Shapin, S. (Eds.). (1998). Science incarnate: Historical embodiments of natural knowledge. Chicago, IL: The University of Chicago Press.

Leach, J., \& Paulsen, A. C. (1999). Practical work in science education: Recent research studies. Studies in Science Education, 33, 168-169.

Lindgren, R., \& Johnson-Glenberg, M. (2013). Emboldened by embodiment: Six precepts for research on embodied learning and mixed reality. Educational Researcher, 42(8), 445-452. 
Little, A. J., \& León de la Barra, B. A. (2009). Attracting girls to science, engineering and technology: an Australian perspective. European Journal of Engineering Education, 34(5), 439-445.

Lowe, D., Newcombe, P., \& Stumpers, B. (2013). Evaluation of the Use of Remote Laboratories for Secondary School Science Education. Research in Science Education, 43(3), 1197-1219.

Martindill, D., \& Wilson, E. (2014). Rhetoric or reality? A case study into how, if at all, practical work supports learning in the classroom International Journal for Lesson and Learning Studies, 4(1), 39-55.

Mazzei, L. (2014). Beyond an Easy Sense: A Diffractive Analysis. Qualitative Inquiry, 20(6), $742-746$.

Mercer, N., Dawes, L., Wegerif, R., \& Sams, C. (2004). Reasoning as a scientist: ways of helping children to use language to learn science. British Educational Research Journal, 30(3), 359-377.

Mercer, N., Hennessy, S., \& Warwick, P. (2010). Using interactive whiteboards to orchestrate classroom dialogue. Technology, Pedagogy \& Education, 19(2), 195-209.

Mercer, N., \& Howe, C. (2012). Explaining the dialogic processes of teaching and learning: the value and potential of sociocultural theory. Learning, Culture and Social Interaction, 1(1), 12-21.

Mercer, N., Warwick, P., Kershner, R., \& Staarman, J. K. (2010). Can the interactive whiteboard help to provide "dialogic space" for children's collaborative activity? Language and Education, 24(5), 367-384.

Merleau-Ponty, M. (1968). The Visible and the Invisible. Evanston, IL: Northwestern University Press.

Meyer, A. A., \& Lederman, N. G. (2013). Inventing Creativity: An Exploration of the Pedagogy of Ingenuity in Science Classrooms. School Science \& Mathematics, 113(8).

Millar, R., \& Abrahams, I. (2009). Practical work: making it more effective. School Science Review, 91(334), 59-64.

Millar, R., \& Osborne, J. (1998). Beyond 2000: Science Education for the Future. London: King's College London.

Murcia, K., \& Sheffield, R. (2010). Talking about science in interactive whiteboard classrooms. Australasian Journal of Educational Technology, 26(4), 417-431. 
Orlander, A. A., \& Wickman, P. O. (2011). Bodily experiences in secondary school biology. Cultural Studies of Science Education, 6(3), 569-594.

Osborne, J., (1996). Beyond constructivism. Science Education, 80(1), 53-82.

Osborne, J., \& Collins, S. (2001). Pupils' views of the role and value of the science curriculum: a focus-group study. International Journal of Science Education, 23(5).

Osborne, J., Erduran, S., \& Simon, S. (2004). Enhancing the Quality of Argumentation in School Science. Journal of Research in Science Teaching, 41(10), 994-1020.

Osborne, J. (1998). Science education without a laboratory. In J. Wellington (Ed.), Practical work in school science: Which way now? (pp. 156-173). London: Routledge.

Otrel-Cass, K. (2018). Sensory Science Education. In K. Otrel-Cass, M. Krabbe Sillasen \& A. Arvola Orlander (Eds.), Cultural, Social and Political Perspectives in Science Education: A Nordic View. Netherlands: Springer.

Padalkar, S., \& Ramadas, J. (2011). Designed and spontaneous gestures in elementary astronomy education. International Journal of Science Education, 33(12), 17031739.

Potvin, P., \& Hasni, A. (2014). Interest, motivation and attitude towards science and technology at K-12 levels: a systematic review of 12 years of educational research. Studies in Science Education, 50(1), 85-129.

Pozzer-Ardenghi, L., \& Roth, W. M. (2004). Photographs in lectures: Gestures as meaning-making resources. Linguistics and Education, 15(3), 275-293.

Reiner, M. (1999). Conceptual construction of fields through tactile interface. Interactive Learning Environments, 7(1), 31-55.

Rennie, L. J. (2014). Learning science outside of school. In N. G. Lederman \& S. K. Abell (Eds.), Handbook of Research on Science Education, Volume 2 (pp. 120144). New York: Routledge.

Rivet, A. E., \& Kastens, K. A. (2012). Developing a construct-based assessment to examine students' analogical reasoning around physical models in Earth Science. Journal of Research in Science Teaching, 49(6), 713-743.

Roehl, T. (2012). From witnessing to recording - material objects and the epistemic configuration of science classes. Pedagogy, Culture \& Society, 20(1), 49-70.

Roscoe, N. (2007). Carrying the flag for practical biology. Journal of Biological Education (Society of Biology), 41(2), 89-89. 
Roth, W.-M, \& Jornet, A. (2014). Toward a Theory of Experience. Science Education, 98(1).

Roth, W.-M., \& Lawless, D. (2002). Scientific investigations, metaphorical gestures, and the emergence of abstract scientific concepts, 12, 285-304.

Roth, W.-M.., \& Welzel, M. (2001). From activity to gestures and scientific language. Journal of Research in Science Teaching, 38(1), 103-136.

Ruthven, K., Mercer, N., Taber, K. S., Guardia, P., Hofmann, R., Ilie, S., . . Riga, F. (2017). A research-informed dialogic-teaching approach to early secondary school mathematics and science: the pedagogical design and field trial of the epiSTEMe intervention. Research Papers in Education, 32(1), 18-40.

Sakr, M., Jewitt, C., \& Price, S.. (2014). The semiotic work of the hands in scientific enquiry. Classroom Discourse, 5(1), 51-70.

Scantlebury, K., \& Milne, C. (Eds.). (2019). Material Practice and Materiality: Too Long Ignored in Science Education. Switzerland: Springer.

Science Community Representing Education. (2008). Practical Work in Science: A Report and Proposal for a Strategic Framework. London: Science Community Representing Education.

Schoultz, J., Saljo, R., \& Wyndhamn, J. (2001). Heavenly talk: Discourse, artefacts, and children's understanding of elementary astronomy. Human Development, 44 , $103-118$.

Singer, M., Radinsky, J., \& Goldman, S. R. (2008). The role of gesture in meaning construction. Discourse Processes, 45(4-5), 365-386.

Swain, J., Monk, M., \& Johnson, S.. (1999). A comparative study of attitudes to the aims of practical work in science education in Egypt, Korea and the UK. International Journal of Science Education, 21(12), 1311-1323.

Thomas, G., \& McRobbie, C. (2013). Eliciting Metacognitive Experiences and Reflection in a Year 11 Chemistry Classroom: An Activity Theory Perspective. Journal of Science Education \& Technology, 22(3), 300-313.

Toon, A. (2011). Playing with molecules. Studies in History and Philosophy of Science Part A, 42(4), 580-589.

Toulmin, S. (1972). Human understanding: The collective use and evolution of concepts. Princeton, NJ: University of Princeton Press.

Triona, L., \& Klahr, D. (2003). Point and click or grab and heft: Comparing the influence of physical and virtual instructional materials on elementary school 
students' ability to design experiments. Cognition and Instruction, 21(2), 149173.

Tsai, C. C. (2003). Taiwanese science student's and teachers' perceptions of the laboratory learning environments: Exploring epistemological gaps. International Journal of Science Education, 25(7), 847-860.

Tytler, R., Prain, V., Hubber, P., \& Waldrip, B. (Eds.). (2013). Constructing Representations to Learn in Science. Rotterdam: Sense.

Van Booven, C. D. (2015). Revisiting the Authoritative-Dialogic Tension in InquiryBased Elementary Science Teacher Questioning. International Journal of Science Education, 37(8), 1182-1201.

Veloso, L., \& Marques, J. S. (2017). Designing science laboratories: learning environments, school architecture and teaching and learning models. Learning Environments Research, 20(2), 221-248.

Vosniadou, S., Skopeliti, I., \& Ikospentaki, K. (2005). Reconsidering the role of artefacts in reasoning: Children's understanding of the globe as a model of the earth. Learning and Instruction, 15, 333-351.

Watson, J. D. (1968). The double helix: A personal account of the discovery of the structure of DNA. London: Weidenfeld and Nicolson.

Wegerif, Rupert. (2011a). Towards a dialogic theory of how children learn to think. Thinking Skills \& Creativity, 6(3), 179-190.

Wegerif, Rupert (2011b) From Dialectic to Dialogic: A response to Wertsch and Kazak. In Koschmann, T. (Ed). Theories of learning and studies of instructional practice (pp. 201-221). Springer, New York, NY.

Wegerif, Rupert. (2018). A dialogic theory of teaching thinking. In L. Kerslake \& R. Wegerif (Eds.), The Theory of Teaching Thinking. London: Routledge.

Wellington, J., \& Ireson, G. (2017). Science Teaching, Science Learning (Fourth Edition). London: Routledge.

Wesberg, S. M., \& Newcombe, N. S. (2017). Embodied cognition and STEM learning: overview of a topical collection in CR:PI. Cognitive Research: Principles and Implications, 2(7).

Yoon, H.-G, \& Kim, M. (2010). Collaborative Reflection through Dilemma Cases of Science Practical Work during Practicum. International Journal of Science Education, 32(3). 
Zacharia, Z. C. (2015). Examining whether touch sensory feedback is necessary for science learning through experimentation: A literature review of two different lines of research across K-16. Educational Research Review, 16, 116-137.

Zacharia, Z. C., \& de Jong, T. (2014). The effects on students' conceptual understanding of electric circuits of introducing virtual manipulatives within a physical manipulatives-oriented curriculum. Cognition and Instruction, 32(2), $101-158$.

Zacharia, Z. C., Loizou, E., \& Papaevripidou, M. (2012). Is physicality an important aspect of learning through science experimentation among kindergarten students? Early Childhood Research Quarterly, 27(3), 447-457.

Zacharia, Z. C., \& Olympiou, G. (2011). Physical versus virtual manipulative experimentation in physics learning. Learning and Instruction, 21(3), 317-331. 